Supporting Information for

\title{
Achieving Recurrent Sensing of Nitroxyl by Tuning the Ligand Environment of Azamacrocyclic Copper(II) Complexes
}

Sunghee Kim, Mikael A. Minier, Andrei Loas, Sabine Becker, Fang Wang, and Stephen J. Lippard*

Department of Chemistry, Massachusetts Institute of Technology, Cambridge, Massachusetts 02139, United States

1. Materials and Methods.

2. Synthesis of Copper (II)/(I) Complexes.

3. X-ray Crystallography.

4. Cyclic Voltammetry (CV) Data.

5. Reactivity of 5 toward $\mathrm{HNO}, \mathrm{NO}, \mathrm{H}_{2} \mathrm{~S}, \mathrm{GSH}, \mathrm{Cys}$, Met and $\mathrm{NaNO}_{2}$ in $\mathrm{pH} 7$ Buffer.

6. Reactivity of $\mathbf{5}$ toward HNO in Methanol.

7. Reactivity of $\mathbf{5}$ toward $\mathrm{HO}^{-}$in $\mathrm{pH} 7$ Buffer and Methanol.

8. Reactivity of 6 toward HNO in $\mathrm{pH} 7$ Buffer.

9. Reactivity of 6 toward $\mathrm{HO}^{-}$in $\mathrm{pH} 7$ Buffer and Methanol.

10. Reactivity of 6 toward $\mathrm{NO}, \mathrm{NaNO}_{2}, \mathrm{H}_{2} \mathrm{~S}$, GSH, Cys, and Met in pH 7 Buffer.

11. Reactivity of $\mathbf{6}$ toward $\mathrm{HNO}$ in the Presence of 100 Equiv of $\mathrm{NaNO}_{2}$ in Buffer.

12. Reactivity of 6 toward HNO Monitored by ${ }^{1} \mathrm{H}$ NMR Spectroscopy.

13. Reactivity of 6 toward $\mathrm{HNO}$ at Different $\mathrm{pH}$ Values.

14. Reactivity of 6 toward HNO and NO in pH 7 Buffer.

15. Reactivity of 7 toward NO in $\mathrm{pH} 7$ Buffer.

16. References. 


\section{Materials and Methods.}

General. All solvents and reagents used were of analytical grade and obtained from commercial sources. Piperazine- $N, N$ '-bis(2-ethanesulfonic acid) (PIPES) and $99.999 \% \mathrm{KCl}$ were purchased from Calbiochem. Sodium $\alpha$-oxyhyponitrite $\left(\mathrm{Na}_{2} \mathrm{~N}_{2} \mathrm{O}_{3}\right.$, Angeli's salt) was prepared according to a previously published procedure. ${ }^{1}$ Cyclam (1,4,8,11-tetraazacyclotetradecane, 14- $\left.\mathrm{N}_{4}\right)$ was purchased from Alfa Aesar. 1,8Dimethyl-1,4,8,11-tetraazacyclotetradecane $\quad\left(14-\mathrm{N}_{4}-\mathrm{Me}_{2}\right),{ }^{2} \quad$ 1,4,8-trimethyl-1,4,8,11-tetraazacyclotetradecane (14- $\left.\mathrm{N}_{4}-\mathrm{Me}_{3}\right),{ }^{3} \quad$ 1,4,8,11-tetramethyl-1,4,8,11-tetraazacyclotetradecane $\quad\left(14-\mathrm{N}_{4}-\mathrm{Me}_{4}\right),{ }^{3}$ 1-tosyl1,4,8,11-tetraazacyclotetradecane $\left(14-\mathrm{N}_{4}-\mathrm{Ts}\right),{ }^{3}$ and 1,8-dithia-4,11-diazacyclotetradecane $\left(14-\mathrm{N}_{2} \mathrm{~S}_{2}\right)^{4}$ were synthesized according to previously published procedures. The structural identity and purity of all ligands were verified by ${ }^{1} \mathrm{H}$ NMR spectroscopy (Figures S1-S5) and electrospray ionization mass spectrometry (ESI-MS). Deuterated solvents were purchased from Cambridge Isotope Laboratories (Tewksbury, MA). Nitric oxide (NO) (Airgas, 99\%) was purified by passing through an Ascarite column ( $\mathrm{NaOH}$ fused on silica gel) and a $6 \mathrm{ft}$ coil filled with silica gel that was cooled at $-78^{\circ} \mathrm{C}$ using a dry ice/acetone bath. NO was stored using standard gas bulbs in the glove box. Hydrogen sulfide $\left(\mathrm{H}_{2} \mathrm{~S}\right)$ (Sigma-Aldrich, 99.5\%) was used as received and collected in a $10 \mathrm{~mL}$ Schlenk flask. All stored gases were transferred using Hamilton gastight syringes equipped with a three-way valve and needle outlet. An $\mathrm{O}_{2}$ (Airgas, 99\%) gas stream was passed through a Drierite column prior to use. Synthesis and manipulations of copper complexes were performed according to standard Schlenk techniques or in an MBraun glove box (with $\mathrm{O}_{2}$ and $\mathrm{H}_{2} \mathrm{O}$ levels below $\left.1 \mathrm{ppm}\right)$. Diethyl ether $\left(\mathrm{Et}_{2} \mathrm{O}\right)$, pentane, dichloromethane (DCM), and acetonitrile $(\mathrm{MeCN})$ were purified using a Glass Contour solvent system. HPLC grade methanol and acetone were purchased from Sigma-Aldrich and used without further purification. All aqueous solutions were prepared using deionized water with a resistivity of $18.2 \mathrm{M} \Omega \cdot \mathrm{cm}$, obtained with a Milli-Q water purification system (Millipore). The aqueous buffer used for spectroscopic measurements (50 mM PIPES, $100 \mathrm{mM}$ $\mathrm{KCl}, \mathrm{pH}$ 7.0), was pretreated with Chelex resin (Bio-Rad) to remove residual metal ions in solution.

Instrumentation. Bench-top UV-vis experiments were carried out with a Cary Bio-50 spectrophotometer using $1 \mathrm{~cm}$ airtight quartz cuvettes. ${ }^{1} \mathrm{H}$ NMR spectra were acquired at ambient temperature on a Bruker Avance III 400. Assignment of chemical shifts is based on the 1D spectral data. ${ }^{1} \mathrm{H}$ chemical shifts are reported in ppm relative to $\mathrm{SiMe}_{4}(\delta=0.00)$ and were referenced internally to the residual solvent signals. ${ }^{5}$ Low-resolution ESI-MS spectra were obtained with an Agilent 1100 series LC/MSD mass spectrometer using $\mathrm{MeOH}$ as the carrier solvent. The $\mathrm{pH}$ measurements were performed with a Mettler Toledo FE20 pH meter.

EPR Spectroscopy. EPR measurements were performed at $77 \mathrm{~K}$ in $4 \mathrm{~mm}$ quartz EPR tubes on a Bruker EMX CW EPR instrument equipped with an ER 4199HS cavity and controlled with a Bruker ER 041 XG microwave bridge operating at the X-band ( $\sim 9 \mathrm{GHz})$. The samples were brought out of the glove box in sealed EPR tubes and immediately frozen in liquid nitrogen prior to acquisition of the EPR spectra. EPR spectra were simulated in Matlab using the solid-state/frozen-solution functionality ('pepper') implemented in EasySpin. ${ }^{6}$ 
Cyclic Voltammetry. Cyclic voltammograms were measured using a three-electrode setup with a $2.0 \mathrm{~mm}$ diameter glassy carbon working electrode, a Pt auxiliary electrode, and a $\mathrm{Ag}^{+} / \mathrm{Ag}$ reference electrode in acetonitrile. The solvent contained $0.1 \mathrm{M} n-\mathrm{Bu}_{4} \mathrm{NPF}_{6}$ as the supporting electrolyte. The measurements were performed at room temperature with a VersaSTAT3 potentiostat (Princeton Applied Research) operated with the V3 studio software. Measurements were carried out at $200 \mathrm{mV} \mathrm{s}^{-1}$ on quiescent solutions previously purged with dry $\mathrm{N}_{2}$ for $5 \mathrm{~min}$. Data were referenced externally to the $\mathrm{Fc}^{+} / \mathrm{Fc}$ couple.

X-ray Crystallography. Single crystal X-ray diffraction was performed using suitable crystals of $\left[\mathrm{Cu}^{\mathrm{II}}\left(14-\mathrm{N}_{4}\right)(\mathrm{OTf})_{2}\right]\left(\mathbf{1}, \mathrm{OTf}^{-}=\mathrm{OSO}_{2} \mathrm{CF}_{3}^{-}\right),\left[\mathrm{Cu}^{\mathrm{II}}\left(14-\mathrm{N}_{4}-\mathrm{Me}_{2}\right)(\mathrm{OTf})_{2}\right](\mathbf{2}),\left[\mathrm{Cu}^{\mathrm{II}}\left(14-\mathrm{N}_{4}-\mathrm{Me}_{4}\right)(\mathrm{OTf})_{2}\right]$ (4), $\left[\mathrm{Cu}^{\mathrm{II}}\left(14-\mathrm{N}_{4}-\mathrm{Ts}\right)(\mathrm{OTf})_{2}\right](5),\left[\mathrm{Cu}^{\mathrm{II}}\left(14-\mathrm{N}_{2} \mathrm{~S}_{2}\right)(\mathrm{OTf})_{2}\right](\mathbf{6})$ and $\left[\mathrm{Cu}^{\mathrm{I}}\left(14-\mathrm{N}_{2} \mathrm{~S}_{2}\right)\right]\left(\mathrm{PF}_{6}\right)(7)$, which were mounted on loops with Paratone-N oil and transferred to a $\mathrm{N}_{2}$ cold stream $(100 \mathrm{~K})$ by a KRYO-FLEX lowtemperature apparatus. Data were collected on a Bruker APEX CCD X-ray diffractometer (1, 2, 4, 6, and 7) and a Bruker X8 Kappa DUO four-circle diffractometer equipped with a Bruker APEX2 CCD detector (5) with Mo K $\alpha$ radiation $(\lambda=0.71073 \AA)$ controlled by the APEX2 software package. ${ }^{7}$ Reduction of the data was performed by SAINT. ${ }^{8}$ Empirical absorption corrections were calculated with SADABS ${ }^{9}$ and the space groups were determined by XPREP through the analysis of metric symmetry and systematic absences. The structures for $\mathbf{2 , 4 , 6}$, and $\mathbf{7}$ were solved by direct methods and refined by full-matrix leastsquares based on $F^{2}$ using SHELX 2014. The structures of $\mathbf{1}$ and $\mathbf{5}$ were solved with SHELXT ${ }^{10}$ and were refined by full-matrix least-squares based on $F^{2}$ using SHELXL (rev. 647). Each structure was checked for higher symmetry using PLATON. ${ }^{11}$ All non-hydrogen atoms were located and refined anisotropically. Hydrogen atoms were assigned to idealized positions and given thermal parameters equal to either 1.5 (methyl hydrogen atoms) or 1.2 (non-methyl hydrogen atoms) times the thermal parameters of the atoms to which they were attached. Unless otherwise noted, $\mathrm{N}-\mathrm{H}$ hydrogen atoms were located from electron density maps and $\mathrm{N}-\mathrm{H}$ distances were fixed to idealized values for $100 \mathrm{~K}$. Distance and anisotropic displacement parameter restraints were applied to all disordered atoms. Figures were generated using the Olex2.1 Graphical User Interface. ${ }^{12}$ See Figure S7 and Tables S1-S3 below for crystallographic data and refinement details. The Cambridge Crystallographic Data Centre (CCDC) structures 1450048 (for 1), 1450049 (for 2), 1450050 (for 4), 1450051 (for 5), 1450052 (for 6), and 1450053 (for 7) contain the supplementary crystallographic data for the respective complexes. Specific details about refinement, including disorder, are provided below for individual structures.

Complex 1 crystallized in space group P $\overline{1}$ with 1.5 molecules in the asymmetric unit. All molecules showed a whole molecule disorder. Each molecule was modeled across two positions with the main component occupied at $83.1 \%$ and $90.2 \%$, respectively. The triflate anions were disordered as well and each was modeled in the same two-part disorder as the molecules of the $\mathrm{Cu}$ (II) complex. The formation of hydrogen bonds between the nitrogen $\mathrm{H}$ atoms of the complexes and the $\mathrm{O}$ atoms of the triflate was observed in both parts. The third triflate anion was modeled across two positions as well. The major component of the disorder refined to an occupancy of $94.9 \%$. 
Complex 4 crystallized in the monoclinic space group $\mathrm{P} 2{ }_{1} / \mathrm{c}$ with one half a molecule in the asymmetric unit. The triflate anion was modeled across two positions with the main component occupied at $63.3 \%$.

Complex 5 crystallized in the monoclinic space group $\mathrm{P} 2{ }_{1} / \mathrm{c}$ with one molecule per asymmetric unit. The complex was disordered with its enantiomer, which adopts a similar three dimensional shape as depicted in a cartoon below where blue and orange represent the two enantiomers:

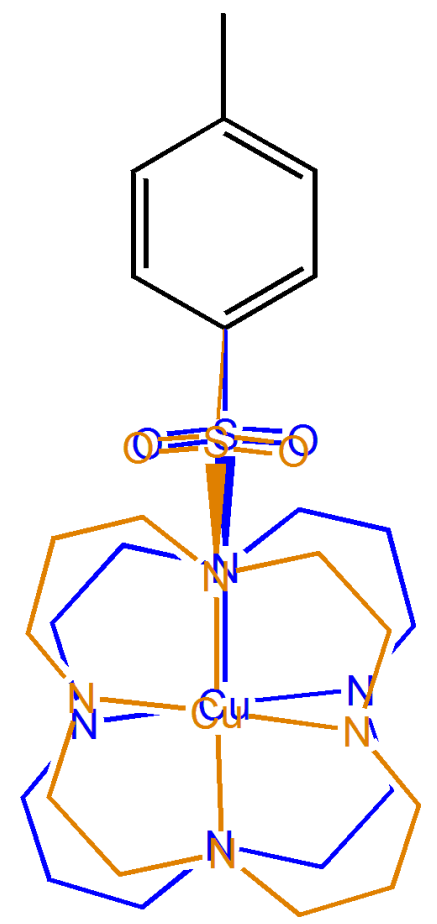

The disorder of the structure can best be described as nearly whole molecule disorder, with the aromatic ring of the tosyl residue remaining approximately in the same position. The major component of the disorder refined to an occupancy of $66.0 \%$. One triflate remains roughly in the same place for both enantiomers. The second triflate was disordered and modeled in the same two-part disorder as the complex. Binding of triflate to copper was only observed for the minor occupied part. The major occupied part formed hydrogen bonds between the nitrogen $\mathrm{H}$ atoms of the complex and the $\mathrm{O}$ atoms of the triflate. All nitrogen $\mathrm{H}$ atoms were assigned to idealized positions. 


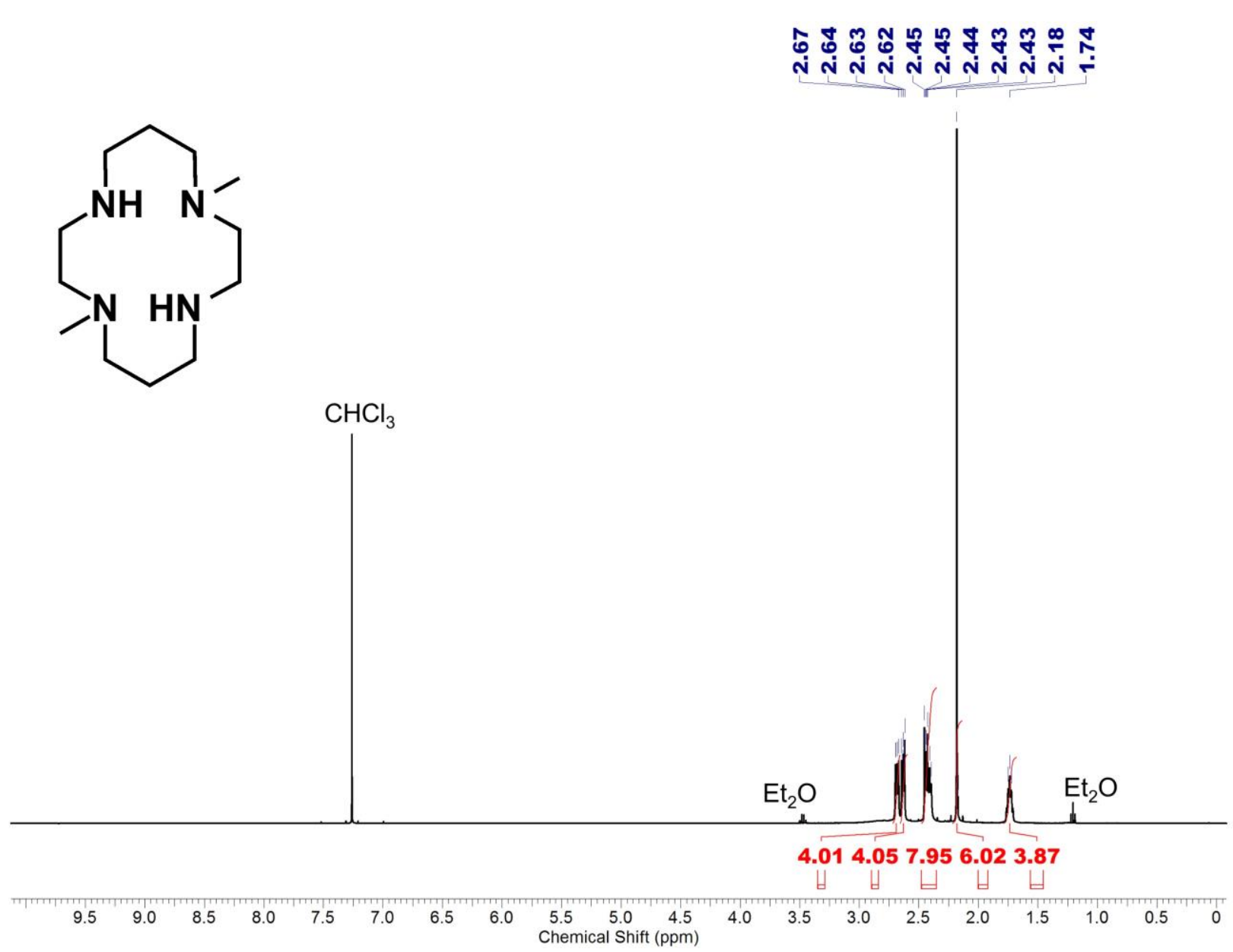

Figure S1. ${ }^{1} \mathrm{H}$ NMR spectrum of $14-\mathrm{N}_{4}-\mathrm{Me}_{2}\left(400 \mathrm{MHz}, \mathrm{CDCl}_{3}\right)$. 


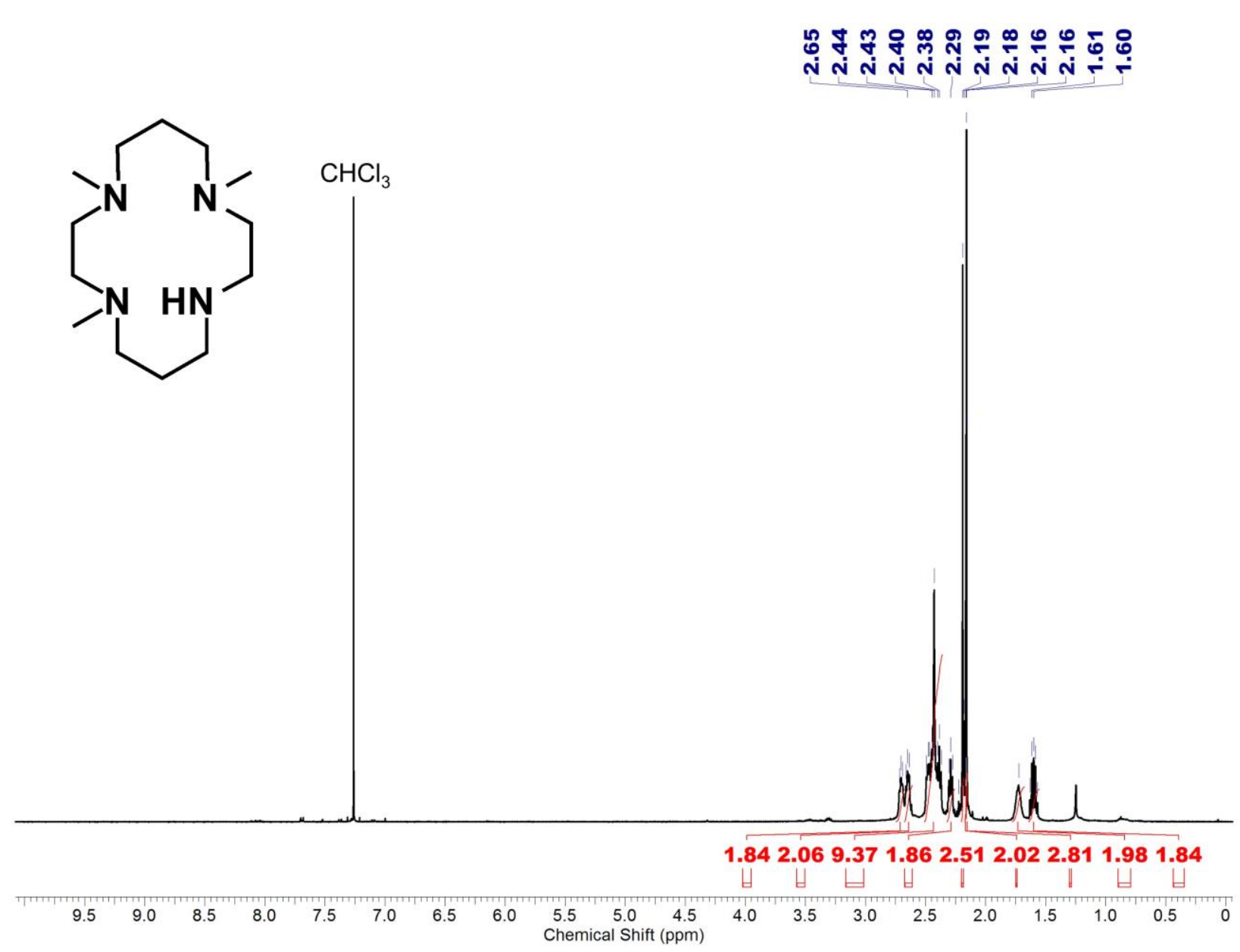

Figure S2. ${ }^{1} \mathrm{H}$ NMR spectrum of $14-\mathrm{N}_{4}-\mathrm{Me}_{3}\left(400 \mathrm{MHz}, \mathrm{CDCl}_{3}\right)$. 


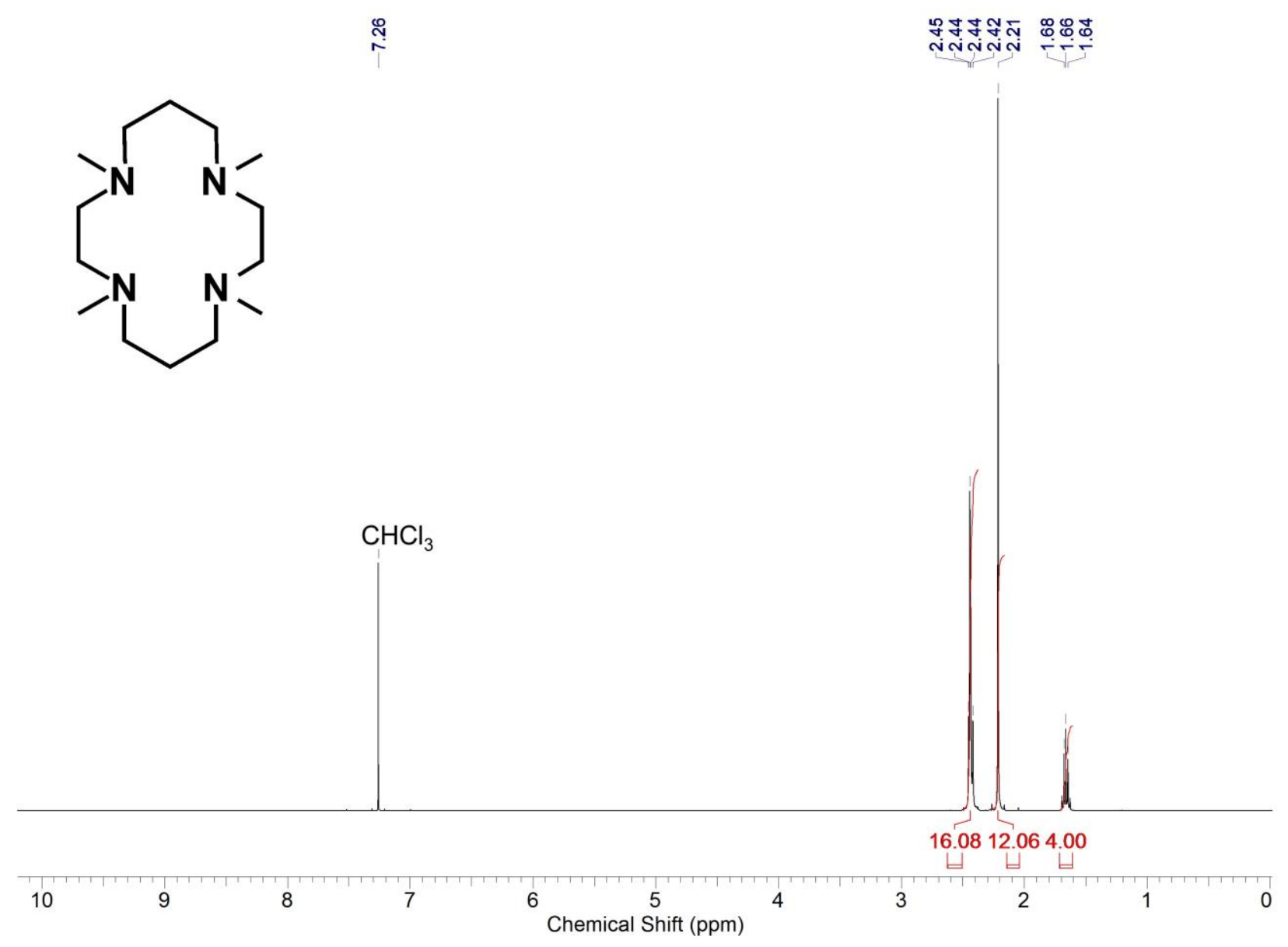

Figure S3. ${ }^{1} \mathrm{H}$ NMR spectrum of $14-\mathrm{N}_{4}-\mathrm{Me}_{4}\left(400 \mathrm{MHz}, \mathrm{CDCl}_{3}\right)$. 


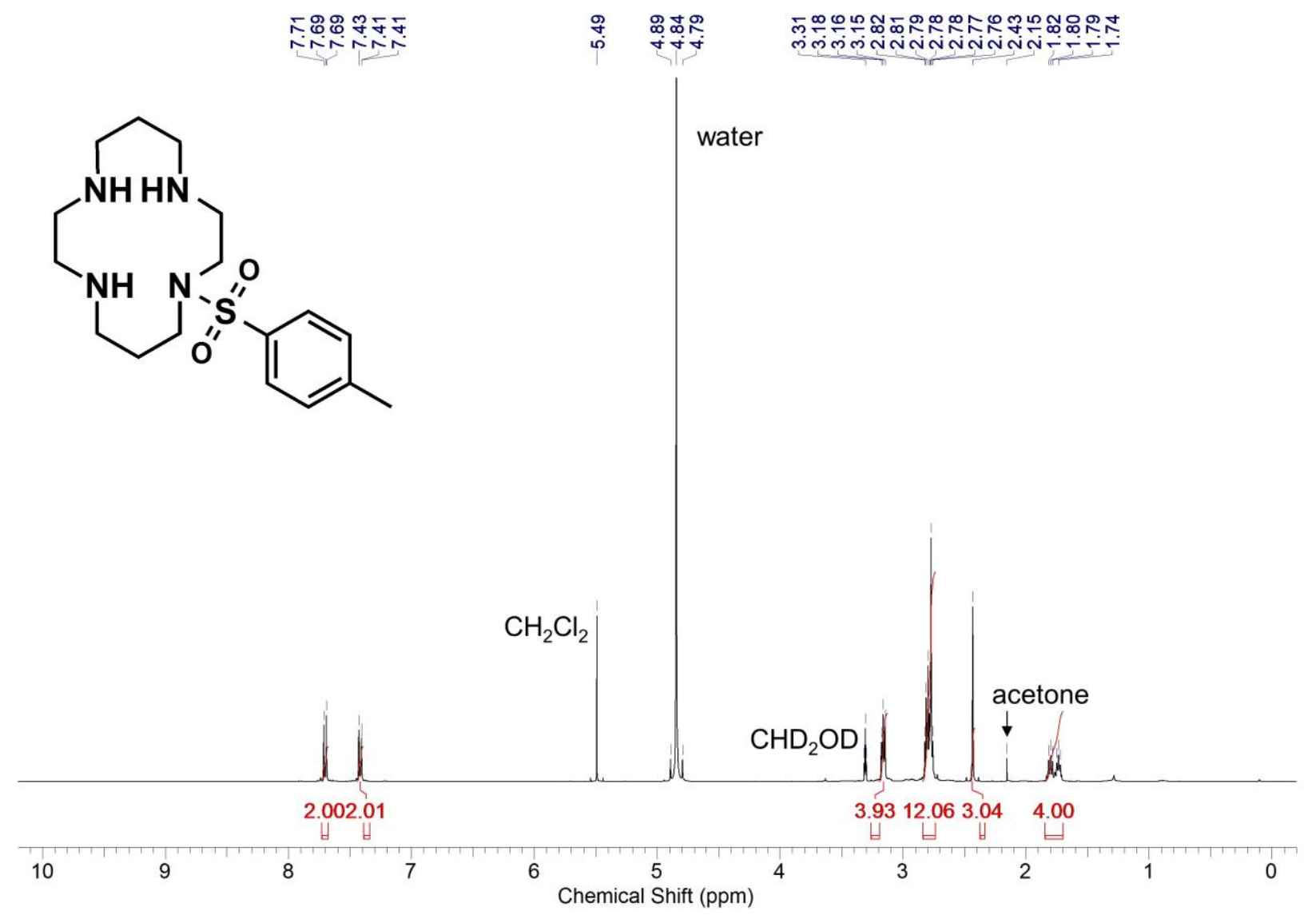

Figure S4. ${ }^{1} \mathrm{H}$ NMR spectrum of $14-\mathrm{N}_{4}-\mathrm{Ts}\left(400 \mathrm{MHz}, \mathrm{CD}_{3} \mathrm{OD}\right)$. 


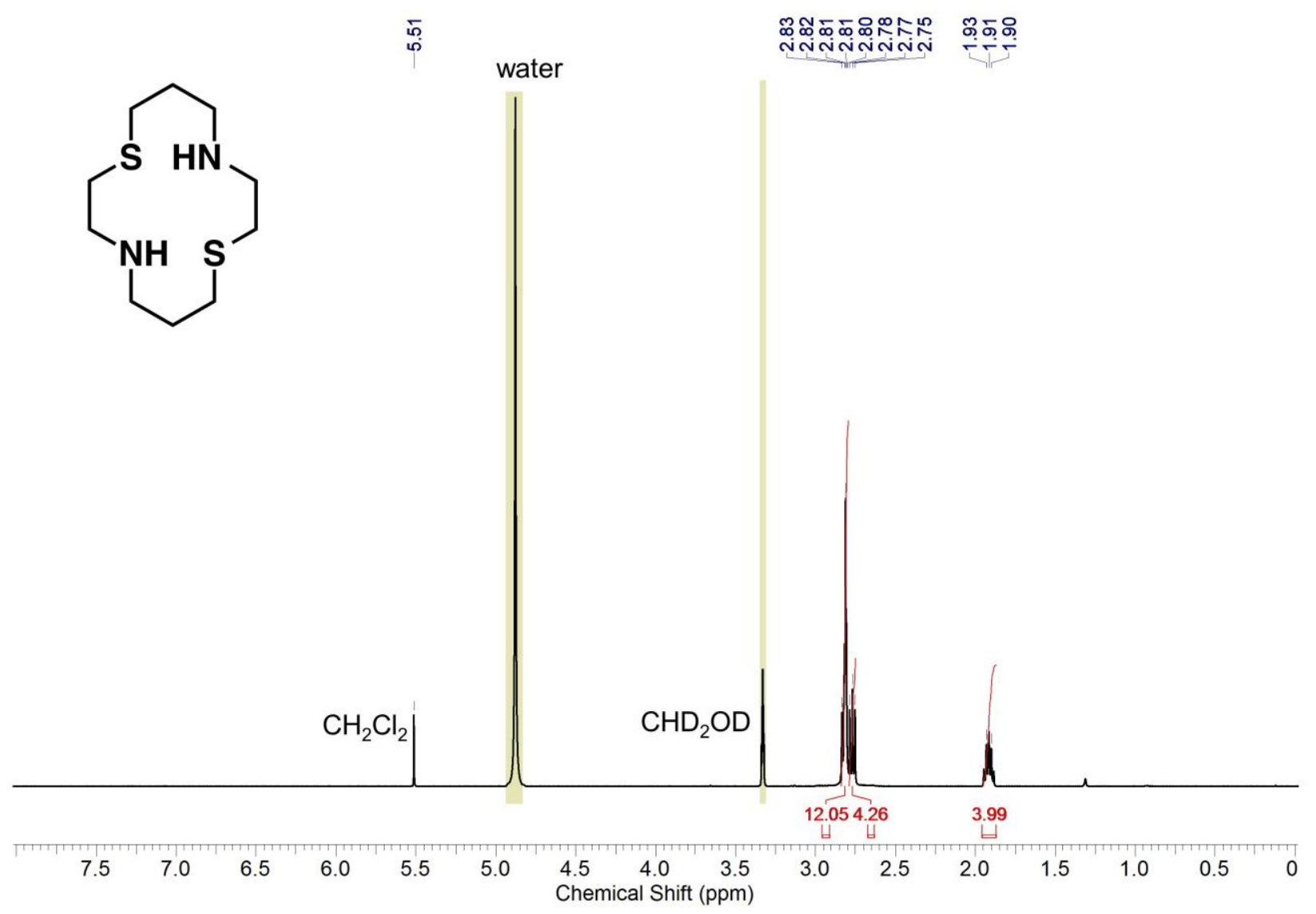

Figure S5. ${ }^{1} \mathrm{H}$ NMR spectrum of $14-\mathrm{N}_{2} \mathrm{~S}_{2}\left(400 \mathrm{MHz}, \mathrm{CD}_{3} \mathrm{OD}\right)$. 


\section{Synthesis of Copper (II)/(I) Complexes.}

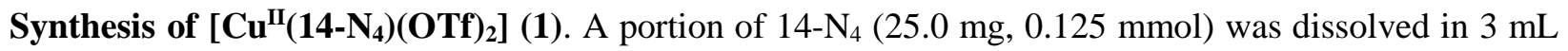
of acetone. To this mixture was added a solution of copper(II) trifluoromethanesulfonate $\left(\mathrm{Cu}(\mathrm{OTf})_{2}, 45.0\right.$ $\mathrm{mg}, 0.125 \mathrm{mmol}$ ) in $3 \mathrm{~mL}$ of acetone in a dropwise manner with stirring at room temperature. After stirring for $15 \mathrm{~min}$ at room temperature, the complex was precipitated as a blue-purple solid by addition of $\mathrm{Et}_{2} \mathrm{O}(50 \mathrm{~mL})$. The supernatant was decanted and the resulting solid was washed two times with $\mathrm{Et}_{2} \mathrm{O}$ and dried under vacuum to afford $58.9 \mathrm{mg}$ of 1 ( $84 \%$ yield). Single crystals were obtained by vapor diffusion of $\mathrm{Et}_{2} \mathrm{O}$ into a solution of the complex in acetone. Anal. calcd for $\mathbf{1}\left(\mathrm{C}_{12} \mathrm{H}_{24} \mathrm{CuF}_{6} \mathrm{~N}_{4} \mathrm{O}_{6} \mathrm{~S}_{2}\right)$ : $\mathrm{C}$, 25.65; H, 4.30; N, 9.97; found: C, 25.76; H, 4.20; N, 9.70; EPR (2 mM in MeOH, $77 \mathrm{~K}, 9.175 \mathrm{GHz}): g_{\|}=$ 2.253, $A_{\|}=159 \mathrm{G} ; g \perp=2.028$ (Figure S6).

Synthesis of $\left[\mathrm{Cu}^{\mathrm{II}}\left(\mathbf{1 4}-\mathrm{N}_{4}-\mathrm{Me}_{2}\right)(\mathrm{OTf})_{2}\right]$ (2). Compound 2 was prepared in a similar manner to $\left[\mathrm{Cu}^{\mathrm{II}}(14-\right.$ $\left.\left.\mathrm{N}_{4}\right)(\mathrm{OTf})_{2}\right]$ (1), using 14- $\mathrm{N}_{4}-\mathrm{Me}_{2}(21.0 \mathrm{mg}, 0.092 \mathrm{mmol})$ instead of 14-N . Yield: 65\% (36.0 mg). Anal. calcd for $2\left(\mathrm{C}_{14} \mathrm{H}_{28} \mathrm{CuF}_{6} \mathrm{~N}_{4} \mathrm{O}_{6} \mathrm{~S}_{2}\right)$ : C, 28.50; H, 4.78; N, 9.50; found: C, 28.55; H, 4.71; N, 9.24; EPR (2 $\mathrm{mM}$ in $\mathrm{MeOH}, 77 \mathrm{~K}, 9.175 \mathrm{GHz}$ ): $g_{\|}=2.250, A_{\|}=155 \mathrm{G} ; g \perp=2.033$ (Figure S6).

Synthesis of $\left[\mathrm{Cu}^{\mathrm{II}}\left(\mathbf{1 4}-\mathbf{N}_{4}-\mathrm{Me}_{3}\right)(\mathrm{OTf})_{2}\right]$ (3). Compound 3 was prepared in a similar manner to [Cu ${ }^{\mathrm{II}}(14-$ $\left.\left.\mathrm{N}_{4}\right)(\mathrm{OTf})_{2}\right]$ (1), using 14- $\mathrm{N}_{4}-\mathrm{Me}_{3}(26.0 \mathrm{mg}, 0.107 \mathrm{mmol})$ instead of 14-N . Yield: 60\% (38.9 mg). Anal. calcd for $3\left(\mathrm{C}_{15} \mathrm{H}_{30} \mathrm{CuF}_{6} \mathrm{~N}_{4} \mathrm{O}_{6} \mathrm{~S}_{2}\right)$ : C, 29.82; H, 5.01; N, 9.27; found: C, 30.37; H, 4.98; N, 9.10; EPR (2 $\mathrm{mM}$ in $\mathrm{MeOH}, 77 \mathrm{~K}, 9.175 \mathrm{GHz}$ ): $g_{\|}=2.256, A_{\|}=155 \mathrm{G} ; g \perp=2.036$ (Figure S6).

Synthesis of $\left[\mathrm{Cu}^{\mathrm{II}}\left(\mathbf{1 4}-\mathrm{N}_{4}-\mathrm{Me}_{4}\right)(\mathrm{OTf})_{2}\right]$ (4). Compound 4 was prepared in a similar manner to [Cu ${ }^{\mathrm{II}}(14-$ $\left.\left.\mathrm{N}_{4}\right)(\mathrm{OTf})_{2}\right](\mathbf{1})$, using 14- $\mathrm{N}_{4}-\mathrm{Me}_{4}(65.0 \mathrm{mg}, 0.253 \mathrm{mmol})$ instead of 14-N . Yield: 84\% (132 mg). Anal. calcd for $4\left(\mathrm{C}_{16} \mathrm{H}_{32} \mathrm{CuF}_{6} \mathrm{~N}_{4} \mathrm{O}_{6} \mathrm{~S}_{2}\right)$ : C, 31.09; $\mathrm{H}, 5.22 ; \mathrm{N}, 9.06$; found: $\mathrm{C}, 31.23 ; \mathrm{H}, 5.15 ; \mathrm{N}, 8.91$; EPR (2 $\mathrm{mM}$ in $\mathrm{MeOH}, 77 \mathrm{~K}, 9.175 \mathrm{GHz}$ ): $g_{\|}=2.258, A_{\|}=151 \mathrm{G} ; g \perp=2.036$ (Figure S6).

Synthesis of [Cu$\left.{ }^{\text {II }}\left(\mathbf{1 4}-\mathbf{N}_{4}-\mathbf{T s}\right)(\mathbf{O T f})_{2}\right]$ (5). Compound 5 was prepared in a similar manner to [Cu ${ }^{\mathrm{II}}(14-$

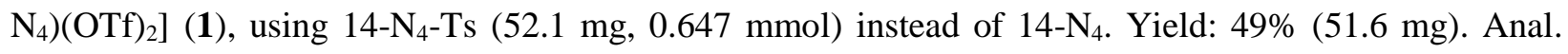
calcd for $5\left(\mathrm{C}_{19} \mathrm{H}_{30} \mathrm{CuF}_{6} \mathrm{~N}_{4} \mathrm{O}_{8} \mathrm{~S}_{3}\right)$ : C, 31.86; $\mathrm{H}, 4.22 ; \mathrm{N}, 7.82$; found: $\mathrm{C}, 31.96$; H, 4.12; N, 7.55; EPR (2 $\mathrm{mM}$ in $\mathrm{MeOH}, 77 \mathrm{~K}, 9.175 \mathrm{GHz}$ ): $g_{\|}=2.242, A_{\|}=149 \mathrm{G} ; g \perp=2.036$ (Figure S6).

Synthesis of $\left[\mathrm{Cu}^{\mathrm{II}}\left(\mathbf{1 4}-\mathrm{N}_{2} \mathrm{~S}_{2}\right)(\mathbf{O T f})_{2}\right]$ (6). Compound 6 was prepared in a similar manner to [Cu ${ }^{\mathrm{II}}(14-$

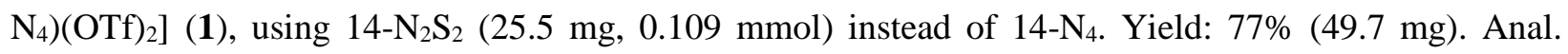
calcd for $6\left(\mathrm{C}_{12} \mathrm{H}_{22} \mathrm{CuF}_{6} \mathrm{~N}_{2} \mathrm{O}_{6} \mathrm{~S}_{4}\right)$ : C, 24.18; H, 3.72; N, 4.70; found: C, 24.33; H, 3.64; N, 4.41; EPR (2 $\mathrm{mM}$ in $\mathrm{MeOH}, 77 \mathrm{~K}, 9.175 \mathrm{GHz}$ ): $g_{\|}=2.221, A_{\|}=181 \mathrm{G} ; g \perp=2.005$ (Figure S6).

Synthesis of $\left[\mathbf{C u}^{\mathrm{I}}\left(\mathbf{1 4}-\mathbf{N}_{2} \mathbf{S}_{2}\right)\right]\left(\mathbf{P F}_{6}\right)$ (7). $\left[\mathrm{Cu}^{\mathrm{I}}\left(\mathrm{CH}_{3} \mathrm{CN}\right)_{4}\right]\left(\mathrm{PF}_{6}\right)(43.9 \mathrm{mg}, 0.118 \mathrm{mmol})$ was dissolved in $2 \mathrm{~mL}$ of $\mathrm{CH}_{2} \mathrm{Cl}_{2}$ in a dry box. To this mixture, a solution of $14-\mathrm{N}_{2} \mathrm{~S}_{2}(27.6 \mathrm{mg}, 0.118 \mathrm{mmol})$ in $\sim 3 \mathrm{~mL}$ of $\mathrm{CH}_{2} \mathrm{Cl}_{2}$ was added dropwise, yielding a colorless solution which was allowed to stir for $2 \mathrm{~min}$. Then, $\sim 60 \mathrm{~mL}$ of degassed pentane $/ \mathrm{Et}_{2} \mathrm{O}(1: 2 \mathrm{v} / \mathrm{v})$ were added to the solution. After $40 \mathrm{~min}$, the supernatant was decanted and the white powder was dried in vacuo to afford $20.8 \mathrm{mg}$ of 7 (39\%). X-ray quality crystals of 7 were obtained by layering dry pentane/ $\mathrm{Et}_{2} \mathrm{O}$ on top of a $\mathrm{CH}_{2} \mathrm{Cl}_{2}$ solution of the complex. Anal. calcd for 7 $\left(\mathrm{C}_{10} \mathrm{H}_{22} \mathrm{CuF}_{6} \mathrm{~N}_{2} \mathrm{PS}_{2}\right)$ : C, 27.12; H, 5.01; N, 6.32; found: C, 27.29; H, 4.91; N, 6.30. 


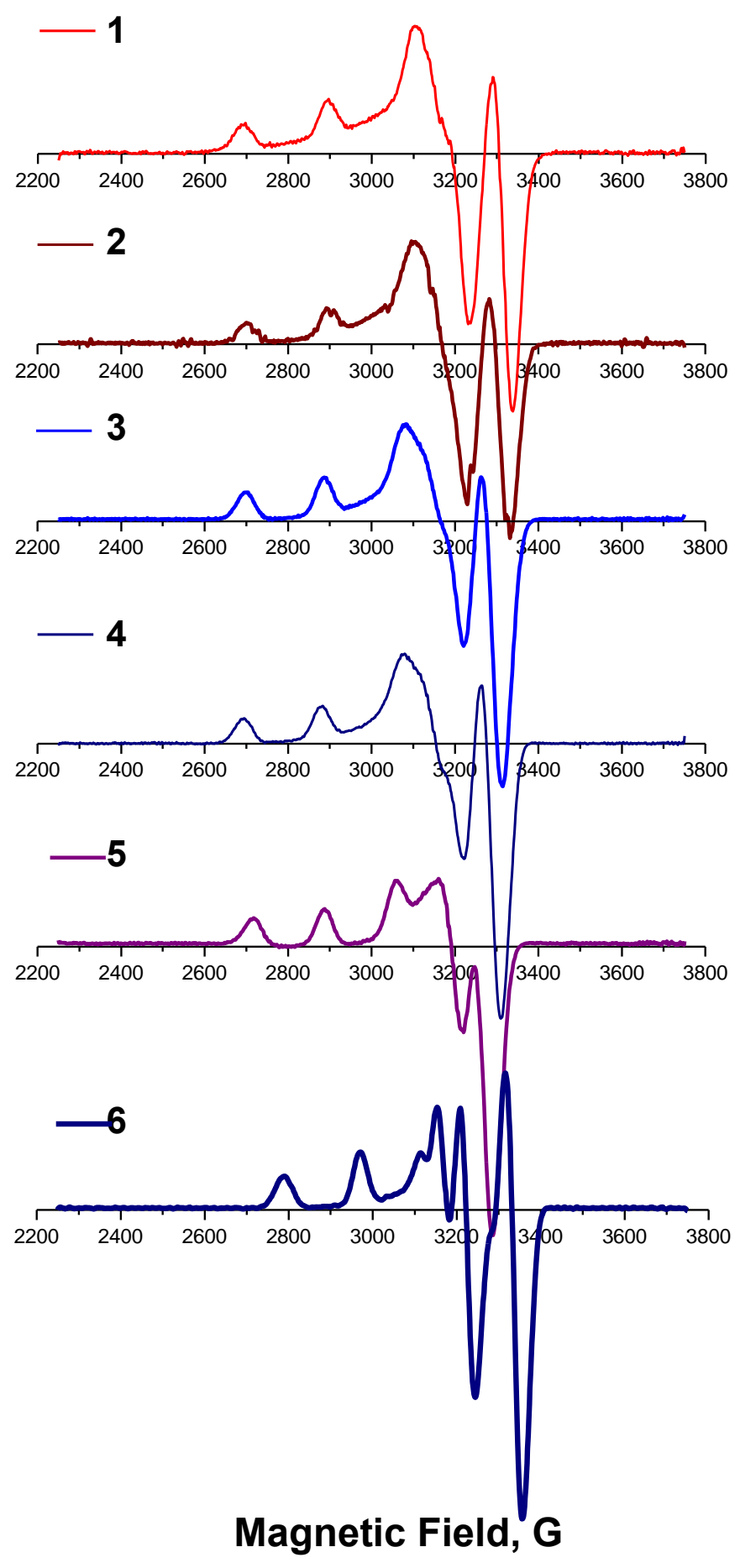

Figure S6. X-band EPR spectra of $2.0 \mathrm{mM}$ solutions of $\left[\mathrm{Cu}^{\mathrm{II}}\left(14-\mathrm{N}_{4}\right)(\mathrm{OTf})_{2}\right](\mathbf{1}),\left[\mathrm{Cu}^{\mathrm{II}}\left(14-\mathrm{N}_{4}-\mathrm{Me}_{2}\right)(\mathrm{OTf})_{2}\right]$ (2), $\left[\mathrm{Cu}^{\mathrm{II}}\left(14-\mathrm{N}_{4}-\mathrm{Me}_{3}\right)(\mathrm{OTf})_{2}\right](\mathbf{3}),\left[\mathrm{Cu}^{\mathrm{II}}\left(14-\mathrm{N}_{4}-\mathrm{Me}_{4}\right)(\mathrm{OTf})_{2}\right](4),\left[\mathrm{Cu}^{\mathrm{II}}\left(14-\mathrm{N}_{4}-\mathrm{Ts}\right)(\mathrm{OTf})_{2}\right](\mathbf{5})$ and $\left[\mathrm{Cu}^{\mathrm{II}}(14-\right.$ $\left.\left.\mathrm{N}_{2} \mathrm{~S}_{2}\right)(\mathrm{OTf})_{2}\right](6)$ in methanol. Collection parameters: temperature, $77 \mathrm{~K}$; modulation amplitude, $20 \mathrm{G}$; microwave power, $0.02 \mathrm{~mW}$ at $9.175 \mathrm{GHz}$. 


\section{X-ray Crystallography.}

(a)
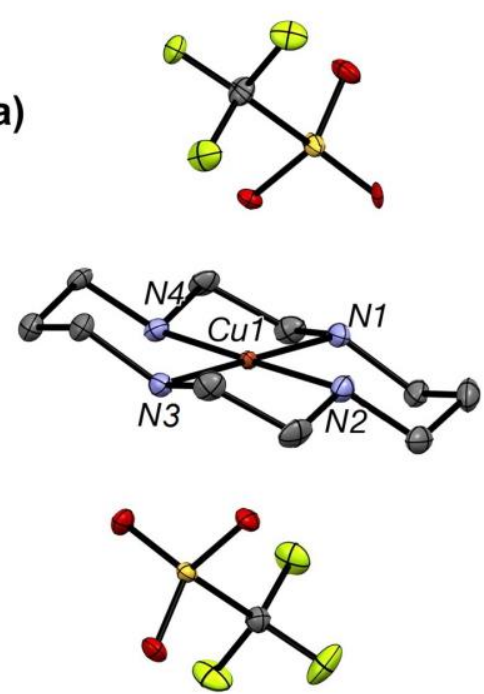

(b)

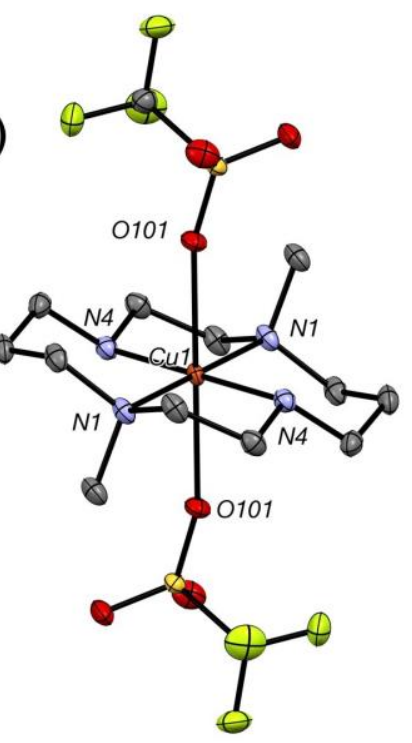

(e)

(d)
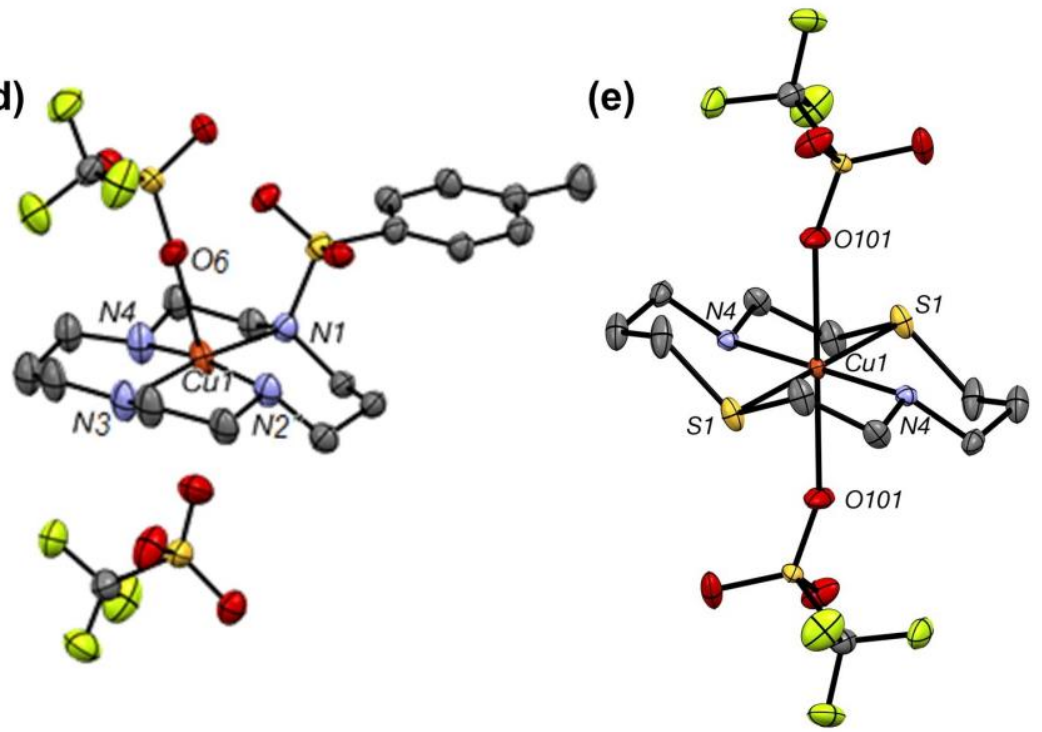

(c)

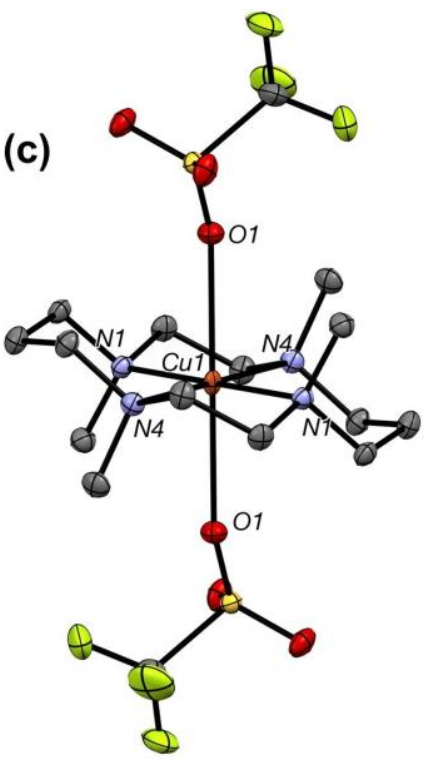

(f)
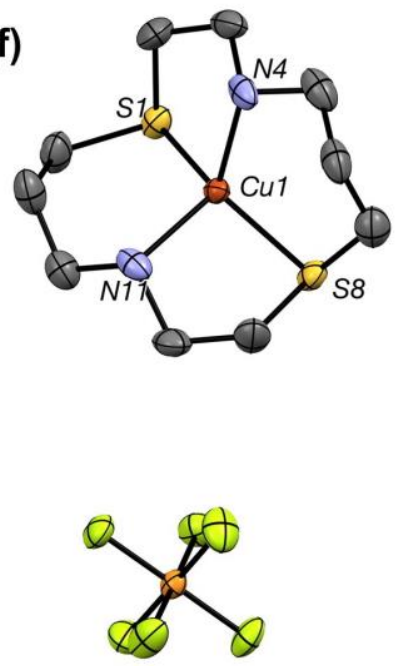

Figure S7. ORTEP representations of the X-ray crystal structures of (a) $\left[\mathrm{Cu}^{\mathrm{II}}\left(14-\mathrm{N}_{4}\right)(\mathrm{OTf})_{2}\right]$ (1), (b) $\left[\mathrm{Cu}^{\mathrm{II}}\left(14-\mathrm{N}_{4}-\mathrm{Me}_{2}\right)(\mathrm{OTf})_{2}\right]$ (2), (c) $\left[\mathrm{Cu}^{\mathrm{II}}\left(14-\mathrm{N}_{4}-\mathrm{Me}_{4}\right)(\mathrm{OTf})_{2}\right] \quad$ (4), (d) $\left[\mathrm{Cu}^{\mathrm{II}}\left(14-\mathrm{N}_{4}-\mathrm{Ts}\right)(\mathrm{OTf})_{2}\right]$ (5), (e) $\left[\mathrm{Cu}^{\mathrm{II}}\left(14-\mathrm{N}_{2} \mathrm{~S}_{2}\right)(\mathrm{OTf})_{2}\right]$ (6) and (f) $\left[\mathrm{Cu}^{\mathrm{I}}\left(14-\mathrm{N}_{2} \mathrm{~S}_{2}\right)\right]\left(\mathrm{PF}_{6}\right)$ (7). Thermal ellipsoids are shown at $50 \%$ probability. Solvent molecules and hydrogen atoms are omitted for clarity. 
Table S1. X-ray Crystallographic Data for Compounds 1, 2, 4, and 5 at $100 \mathrm{~K}$

\begin{tabular}{|c|c|c|c|c|}
\hline & 1 & 2 & 4 & 5 \\
\hline Empirical formula & $\mathrm{C}_{12} \mathrm{H}_{24} \mathrm{CuF}_{6} \mathrm{~N}_{4} \mathrm{O}_{6} \mathrm{~S}_{2}$ & $\mathrm{C}_{14} \mathrm{H}_{28} \mathrm{CuF}_{6} \mathrm{~N}_{4} \mathrm{O}_{6} \mathrm{~S}_{2}$ & $\mathrm{C}_{16} \mathrm{H}_{32} \mathrm{CuF}_{6} \mathrm{~N}_{4} \mathrm{O}_{6} \mathrm{~S}_{2}$ & $\mathrm{C}_{19} \mathrm{H}_{30} \mathrm{CuF}_{6} \mathrm{~N}_{4} \mathrm{O}_{8} \mathrm{~S}_{3}$ \\
\hline Formula weight & 562.01 & 590.06 & 618.11 & 716.19 \\
\hline Crystal system & Triclinic & Triclinic & Monoclinic & Monoclinic \\
\hline Space group & $\mathrm{P} \overline{1}$ & $\mathrm{P} \overline{1}$ & $\mathrm{P} 2{ }_{1} / \mathrm{c}$ & $\mathrm{P} 2_{1} / \mathrm{c}$ \\
\hline a, $\AA$ & $11.711(3)$ & $8.3746(5)$ & $8.3832(5)$ & $13.458(4)$ \\
\hline $\mathbf{b}, \AA$ & $11.804(3)$ & $8.4727(5)$ & $10.2890(7)$ & $25.076(8)$ \\
\hline c, $\AA$ & $13.673(6)$ & $8.7772(5)$ & $14.7151(9)$ & $8.454(2)$ \\
\hline$\alpha,{ }^{\circ}$ & $112.586(6)$ & $76.2590(10)$ & - & - \\
\hline$\beta, \circ$ & 104.970(6) & $83.5120(10)$ & $105.5240(10)$ & 107.299(5) \\
\hline$\gamma,{ }^{\circ}$ & $102.890(4)$ & $64.9280(10)$ & - & - \\
\hline Volume, $\AA^{3}$ & $1571.9(9)$ & $547.91(6)$ & $1222.94(13)$ & $2720.3(7)$ \\
\hline $\mathbf{Z}$ & 3 & 1 & 2 & 4 \\
\hline$\rho_{\text {calcd }}, \mathbf{g} / \mathbf{c m}^{3}$ & 1.781 & 1.788 & 1.679 & 1.746 \\
\hline$\mu, \mathrm{mm}^{-1}$ & 1.332 & 1.278 & 1.150 & 1.125 \\
\hline$\theta$ range, $^{\circ}$ & $1.930-30.833$ & $2.389-29.605$ & $2.446-29.668$ & $1.583-31.504$ \\
\hline Completeness to $\theta, \%$ & 99.4 & 99.9 & 100.0 & 98.6 \\
\hline Reflections collected & 32074 & 10987 & 25604 & 79965 \\
\hline Independent reflections & 9042 & 3026 & 3457 & 8498 \\
\hline $\mathbf{R}$ (int) & 0.0348 & 0.0189 & 0.0203 & 0.0518 \\
\hline Restraints & 920 & 1 & 264 & 84 \\
\hline Parameters & 748 & 155 & 226 & 606 \\
\hline Max, min transmission & $0.7462,0.5921$ & $0.7459,0.6589$ & $0.7459,0.6447$ & $0.7462,0.6631$ \\
\hline $\mathrm{R} 1(\mathrm{wR} 2)[I>2 \sigma(I)]$ & $0.0462(0.1432)$ & $0.0246(0.0648)$ & $0.0277(0.0722)$ & $0.0596(0.1411)$ \\
\hline R1 (wR2) & $0.0555(0.1493)$ & $0.0256(0.0657)$ & $0.0286(0.0729)$ & $0.0847(0.1531)$ \\
\hline Goodness-of-fit on $F^{2}$ & 1.054 & 1.047 & 1.025 & 1.027 \\
\hline Max, min peaks, e/ $/ \AA^{3}$ & $0.606,-0.714$ & $0.702,-0.450$ & $0.733,-0.289$ & $0.788,-1.171$ \\
\hline
\end{tabular}


Table S2. X-ray Crystallographic Data for Compounds 6 and 7 at $100 \mathrm{~K}$

\begin{tabular}{|c|c|c|}
\hline & 6 & 7 \\
\hline Empirical formula & $\mathrm{C}_{12} \mathrm{H}_{22} \mathrm{CuF}_{6} \mathrm{~N}_{2} \mathrm{O}_{6} \mathrm{~S}_{4}$ & $\mathrm{C}_{11} \mathrm{H}_{22} \mathrm{C}_{12} \mathrm{CuF}_{6} \mathrm{~N}_{2} \mathrm{PS}_{2}$ \\
\hline Formula weight & 596.09 & 525.83 \\
\hline Crystal system & Triclinic & Monoclinic \\
\hline Space group & $\mathrm{P} \overline{1}$ & $\mathrm{P} 2{ }_{1} / \mathrm{n}$ \\
\hline a, $\AA$ & $7.8644(8)$ & $8.1903(4)$ \\
\hline b, $\AA$ & $8.2545(9)$ & $17.8549(9)$ \\
\hline c, $\AA$ & $9.6236(9)$ & $13.8014(7)$ \\
\hline 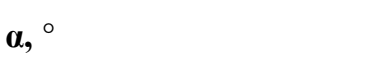 & 83.8430 & - \\
\hline $\boldsymbol{\beta}, \stackrel{\circ}{ }$ & $70.1710(10)$ & $99.5030(10)$ \\
\hline$\gamma, \circ$ & $64.6200(10)$ & - \\
\hline Volume, $\AA^{3}$ & $530.44(9)$ & $1990.58(17)$ \\
\hline $\mathbf{Z}$ & 1 & 4 \\
\hline$\rho_{\text {calcd, }}, \mathbf{g} / \mathrm{cm}^{3}$ & 1.866 & 1.755 \\
\hline$\mu, \mathrm{mm}^{-1}$ & 1.509 & 1.708 \\
\hline$\theta$ range, ${ }^{\circ}$ & $2.252-29.646$ & $1.881-26.463$ \\
\hline Completeness to $\theta, \%$ & 99.9 & 100 \\
\hline Reflections collected & 11396 & 33971 \\
\hline Independent reflections & 2936 & 4112 \\
\hline $\mathbf{R}$ (int) & 0.0213 & 0.0219 \\
\hline Restraints & 1 & 2 \\
\hline Parameters & 145 & 232 \\
\hline Max, min transmission & $0.7459,0.6815$ & $0.7454,0.6288$ \\
\hline $\operatorname{R1}(w R 2)[I>2 \sigma(I)]$ & $0.0261(0.0668)$ & $0.0482(0.1221)$ \\
\hline R1 (wR2) & $0.0276(0.0677)$ & $0.0507(0.1241)$ \\
\hline Goodness-of-fit on $F^{2}$ & 1.054 & 1.085 \\
\hline Max, min peaks, $\mathrm{e} / \AA^{3}$ & $1.155,-0.452$ & $1.178,-0.719$ \\
\hline
\end{tabular}


Table S3. Selected Bond Lengths and Angles of Compounds 1-7

\begin{tabular}{|c|c|c|}
\hline Compound & Bond Lengths (̊̊) & Bond Angles ( $\left(^{\circ}\right)$ \\
\hline$\left[\mathrm{Cu}^{\mathrm{II}}\left(14-\mathrm{N}_{4}\right)(\mathrm{OTf})_{2}\right](\mathbf{1})$ & $\begin{array}{l}\mathrm{Cu}(1)-\mathrm{N}(1): 2.022(2) \\
\mathrm{Cu}(1)-\mathrm{N}(2): 2.027(3) \\
\mathrm{Cu}(1)-\mathrm{N}(3): 2.022(2) \\
\mathrm{Cu}(1)-\mathrm{N}(4): 2.008(2)\end{array}$ & $\begin{array}{l}\mathrm{N}(4)-\mathrm{Cu}(1)-\mathrm{N}(1): 86.09(10) \\
\mathrm{N}(4)-\mathrm{Cu}(1)-\mathrm{N}(3): 95.16(10) \\
\mathrm{N}(1)-\mathrm{Cu}(1)-\mathrm{N}(3): 178.73(9) \\
\mathrm{N}(4)-\mathrm{Cu}(1)-\mathrm{N}(2): 179.22(11) \\
\mathrm{N}(1)-\mathrm{Cu}(1)-\mathrm{N}(2): 93.13(11) \\
\mathrm{N}(3)-\mathrm{Cu}(1)-\mathrm{N}(2): 85.62(11)\end{array}$ \\
\hline$\left[\mathrm{Cu}^{\mathrm{II}}\left(14-\mathrm{N}_{4}-\mathrm{Me}_{2}\right)(\mathrm{OTf})_{2}\right](\mathbf{2})$ & $\begin{array}{l}\mathrm{Cu}(1)-\mathrm{N}(4) \# 1: 2.0051(12) \\
\mathrm{Cu}(1)-\mathrm{N}(4): 2.0051(12) \\
\mathrm{Cu}(1)-\mathrm{N}(1) \# 1: 2.0643(11) \\
\mathrm{Cu}(1)-\mathrm{N}(1): 2.0643(11)\end{array}$ & $\begin{array}{l}\mathrm{N}(4) \# 1-\mathrm{Cu}(1)-\mathrm{N}(4): 180.0 \\
\mathrm{~N}(4) \# 1-\mathrm{Cu}(1)-\mathrm{N}(1) \# 1: 86.61(5) \\
\mathrm{N}(4)-\mathrm{Cu}(1)-\mathrm{N}(1) \# 1: 93.39(5) \\
\mathrm{N}(4) \# 1-\mathrm{Cu}(1)-\mathrm{N}(1): 93.39(5) \\
\mathrm{N}(4)-\mathrm{Cu}(1)-\mathrm{N}(1): 86.61(5) \\
\mathrm{N}(1) \# 1-\mathrm{Cu}(1)-\mathrm{N}(1): 180.0\end{array}$ \\
\hline$\left[\mathrm{Cu}^{\mathrm{II}}\left(14-\mathrm{N}_{4}-\mathrm{Me}_{4}\right)(\mathrm{OTf})_{2}\right](\mathbf{4})$ & $\begin{array}{l}\mathrm{Cu}(1)-\mathrm{N}(1) \# 1: 2.0790(11) \\
\mathrm{Cu}(1)-\mathrm{N}(1): 2.0790(11) \\
\mathrm{Cu}(1)-\mathrm{N}(4) \# 1: 2.0898(11) \\
\mathrm{Cu}(1)-\mathrm{N}(4): 2.0899(11)\end{array}$ & $\begin{array}{l}\mathrm{N}(1) \# 1-\mathrm{Cu}(1)-\mathrm{N}(1): 180.0 \\
\mathrm{~N}(1) \# 1-\mathrm{Cu}(1)-\mathrm{N}(4) \# 1: 86.98(4) \\
\mathrm{N}(1)-\mathrm{Cu}(1)-\mathrm{N}(4) \# 1: 93.02(4) \\
\mathrm{N}(1) \# 1-\mathrm{Cu}(1)-\mathrm{N}(4): 93.02(4) \\
\mathrm{N}(1)-\mathrm{Cu}(1)-\mathrm{N}(4): 86.98(4) \\
\mathrm{N}(4) \# 1-\mathrm{Cu}(1)-\mathrm{N}(4): 180.0\end{array}$ \\
\hline$\left[\mathrm{Cu}^{\mathrm{II}}\left(14-\mathrm{N}_{4}-\mathrm{Ts}\right)(\mathrm{OTf})_{2}\right](\mathbf{5})$ & $\begin{array}{l}\mathrm{Cu}(1)-\mathrm{N}(1): 2.147(8) \\
\mathrm{Cu}(1)-\mathrm{N}(2): 2.036(7) \\
\mathrm{Cu}(1)-\mathrm{N}(3): 2.007(4) \\
\mathrm{Cu}(1)-\mathrm{N}(4): 1.965(5) \\
\mathrm{Cu}(1)-\mathrm{O}(6): 2.532(8)\end{array}$ & $\begin{array}{l}\mathrm{N}(4)-\mathrm{Cu}(1)-\mathrm{N}(3): 95.6(2) \\
\mathrm{N}(4)-\mathrm{Cu}(1)-\mathrm{N}(2): 166.5(3) \\
\mathrm{N}(3)-\mathrm{Cu}(1)-\mathrm{N}(2): 84.0(3) \\
\mathrm{N}(4)-\mathrm{Cu}(1)-\mathrm{N}(1): 84.7(2) \\
\mathrm{N}(3)-\mathrm{Cu}(1)-\mathrm{N}(1): 169.4(3) \\
\mathrm{N}(2)-\mathrm{Cu}(1)-\mathrm{N}(1): 93.2(3)\end{array}$ \\
\hline$\left[\mathrm{Cu}^{\mathrm{II}}\left(14-\mathrm{N}_{2} \mathrm{~S}_{2}\right)(\mathrm{OTf})_{2}\right](\mathbf{6})$ & $\begin{array}{l}\mathrm{Cu}(1)-\mathrm{N}(4): 2.0362(12) \\
\mathrm{Cu}(1)-\mathrm{N}(4) \# 1: 2.0363(12) \\
\mathrm{Cu}(1)-\mathrm{S}(1): 2.3038(4) \\
\mathrm{Cu}(1)-\mathrm{S}(1) \# 1: 2.3038(5)\end{array}$ & $\begin{array}{l}\mathrm{N}(4)-\mathrm{Cu}(1)-\mathrm{N}(4) \# 1: 180.0 \\
\mathrm{~N}(4)-\mathrm{Cu}(1)-\mathrm{S}(1): 87.63(4) \\
\mathrm{N}(4) \# 1-\mathrm{Cu}(1)-\mathrm{S}(1): 92.37(4) \\
\mathrm{N}(4)-\mathrm{Cu}(1)-\mathrm{S}(1) \# 1: 92.37(4) \\
\mathrm{N}(4) \# 1-\mathrm{Cu}(1)-\mathrm{S}(1) \# 1: 87.63(4) \\
\mathrm{S}(1)-\mathrm{Cu}(1)-\mathrm{S}(1) \# 1: 180.0\end{array}$ \\
\hline$\left[\mathrm{Cu}^{\mathrm{I}}\left(14-\mathrm{N}_{2} \mathrm{~S}_{2}\right)\right]\left(\mathrm{PF}_{6}\right)(7)$ & $\begin{array}{l}\mathrm{Cu}(1)-\mathrm{N}(4): 2.083(4) \\
\mathrm{Cu}(1)-\mathrm{N}(11): 2.084(3) \\
\mathrm{Cu}(1)-\mathrm{S}(1): 2.2563(11) \\
\mathrm{Cu}(1)-\mathrm{S}(8): 2.2586(11)\end{array}$ & $\begin{array}{l}\mathrm{N}(4)-\mathrm{Cu}(1)-\mathrm{N}(11): 116.44(13) \\
\mathrm{N}(4)-\mathrm{Cu}(1)-\mathrm{S}(1): 92.65(12) \\
\mathrm{N}(11)-\mathrm{Cu}(1)-\mathrm{S}(1): 106.52(12) \\
\mathrm{N}(4)-\mathrm{Cu}(1)-\mathrm{S}(8): 105.42(12) \\
\mathrm{N}(11)-\mathrm{Cu}(1)-\mathrm{S}(8): 91.44(12) \\
\mathrm{S}(1)-\mathrm{Cu}(1)-\mathrm{S}(8): 145.67(4)\end{array}$ \\
\hline
\end{tabular}


4. Cyclic Voltammetry (CV) Data.

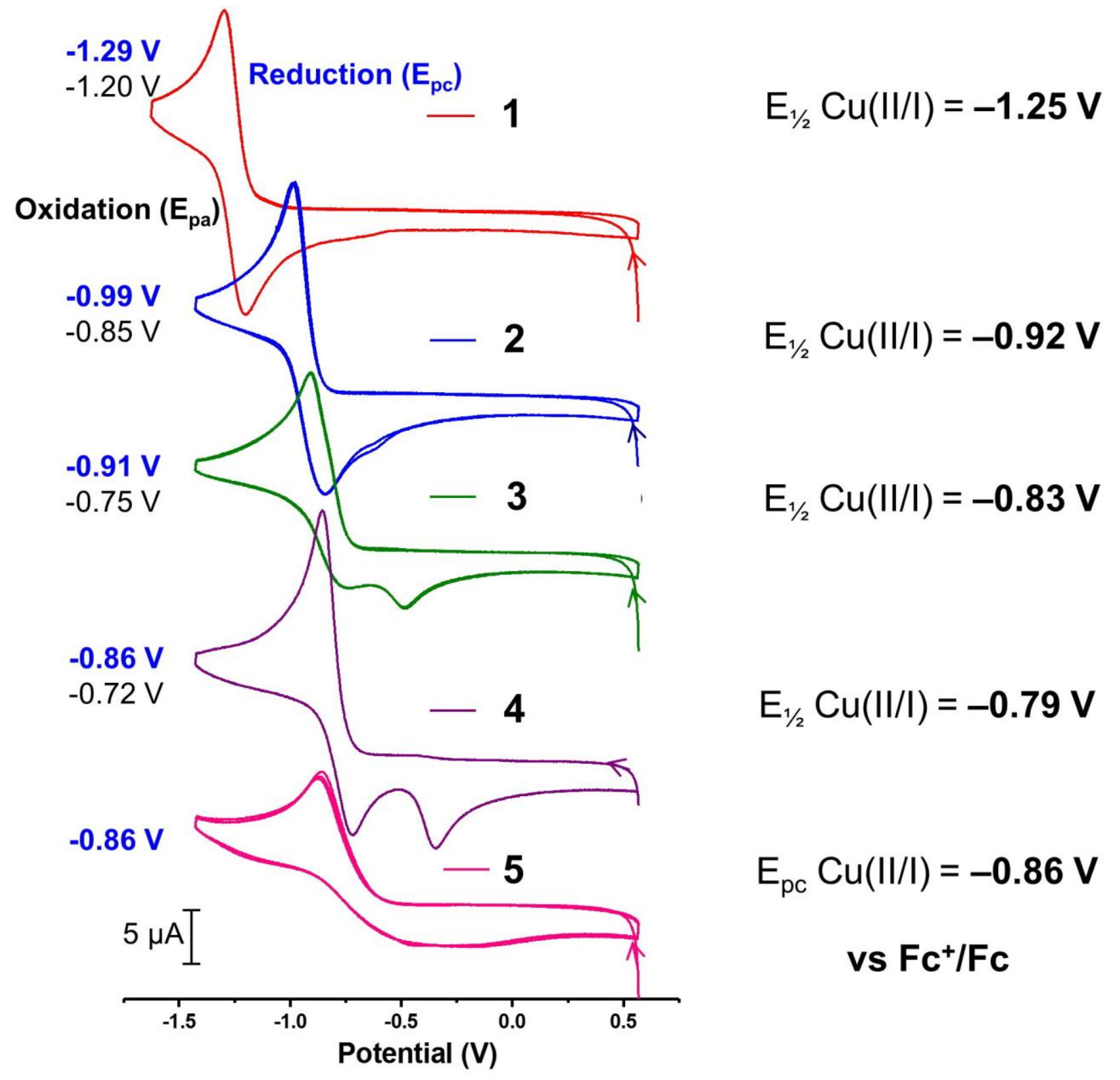

Figure S8. Cyclic voltammograms of $1 \mathrm{mM}$ solutions of compounds $\mathbf{1 - 5}$ in acetonitrile containing $0.1 \mathrm{M}$ $n-\mathrm{Bu}_{4} \mathrm{NPF}_{6}$ as the supporting electrolyte, using a glassy carbon working electrode, Pt auxiliary electrode, and $\mathrm{Ag}^{+} / \mathrm{Ag}$ reference electrode. The potentials are referenced to the $\mathrm{Fc}^{+} / \mathrm{Fc}$ external standard. Scan rate $=$ $200 \mathrm{mV} / \mathrm{s}$. 


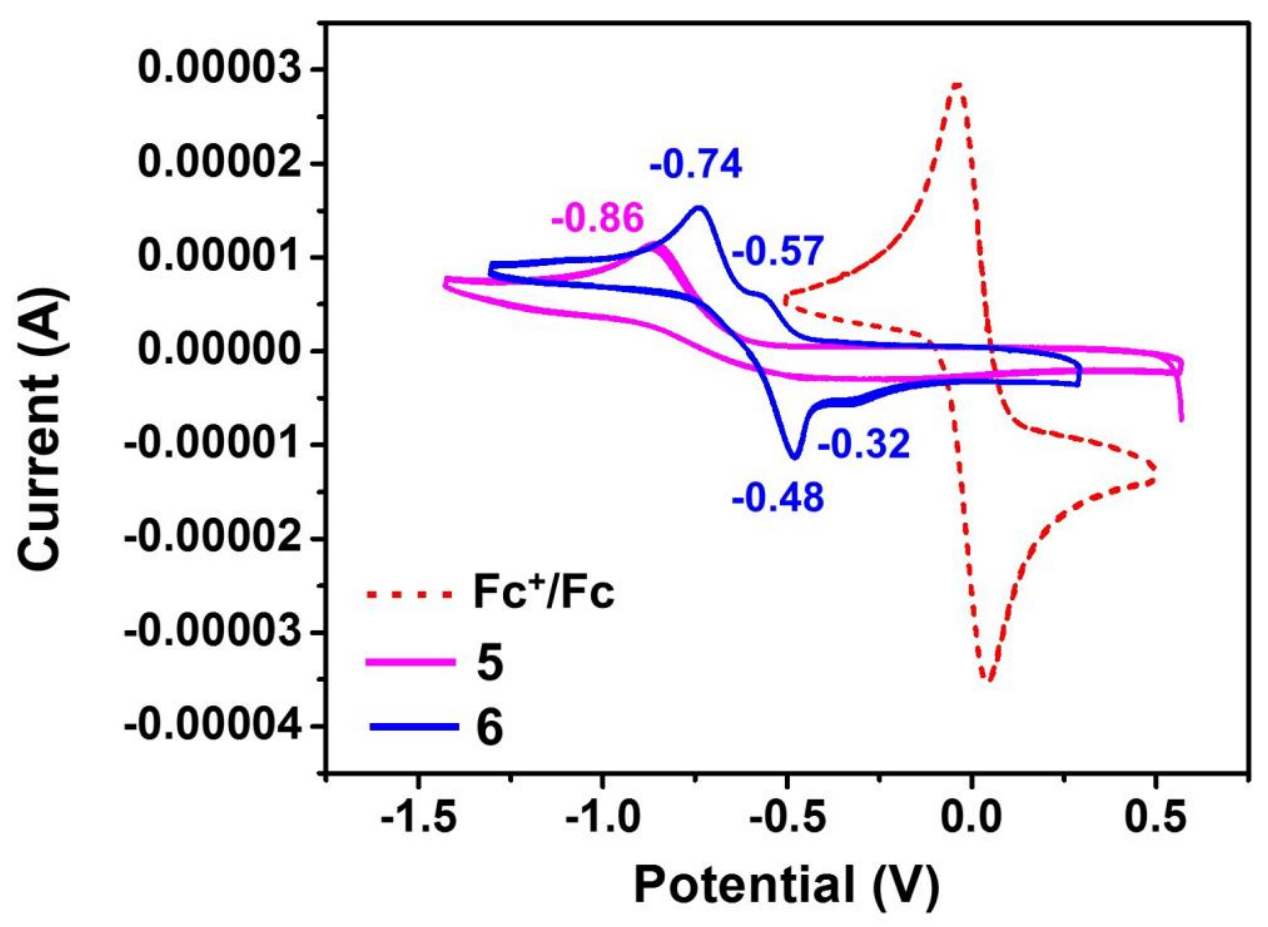

Figure S9. Cyclic voltammograms of $1 \mathrm{mM}$ solutions of compounds 5 and $\mathbf{6}$ in acetonitrile containing 0.1 $\mathrm{M} n-\mathrm{Bu}_{4} \mathrm{NPF}_{6}$ as the supporting electrolyte, using a glassy carbon working electrode, Pt auxiliary electrode, and $\mathrm{Ag}^{+} / \mathrm{Ag}$ reference electrode. The potentials are referenced to the $\mathrm{Fc}^{+} / \mathrm{Fc}$ external standard (shown as the dotted red line). Scan rate $=200 \mathrm{mV} / \mathrm{s}$. 


\section{Reactivity of 5 toward $\mathrm{HNO}, \mathrm{NO}, \mathrm{H}_{2} \mathrm{~S}$, GSH, Cys, Met and $\mathrm{NO}_{2}^{-}$in $\mathrm{pH} 7 \mathrm{Buffer}$}

(a)

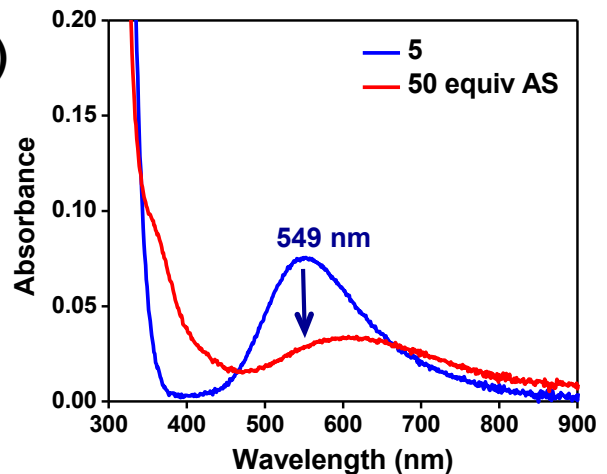

(c)

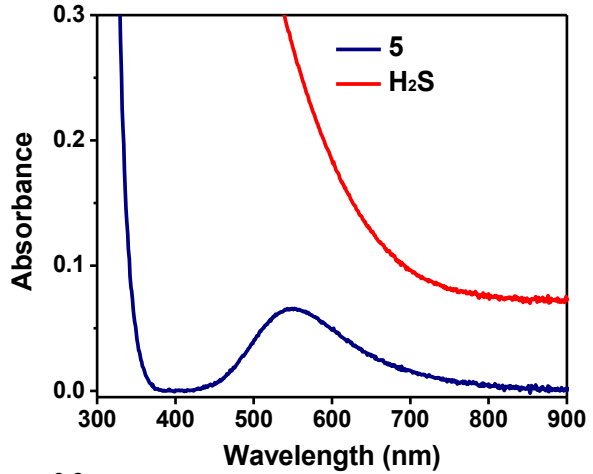

(e)

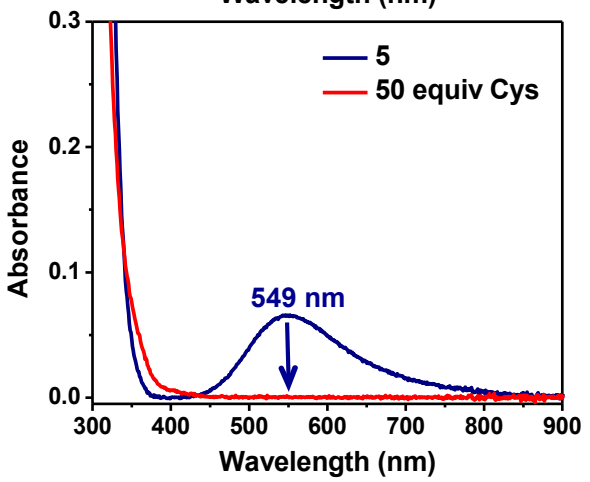

(g)

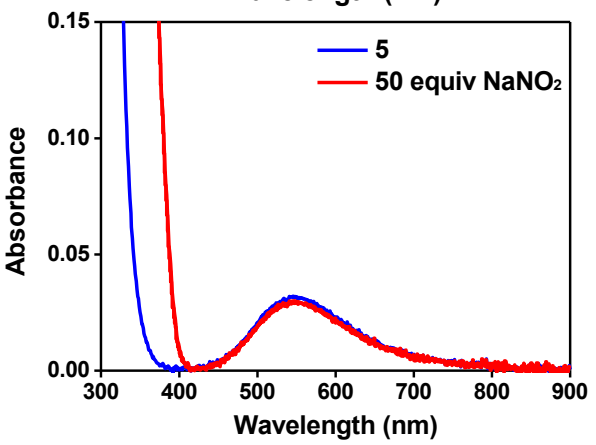

(b)

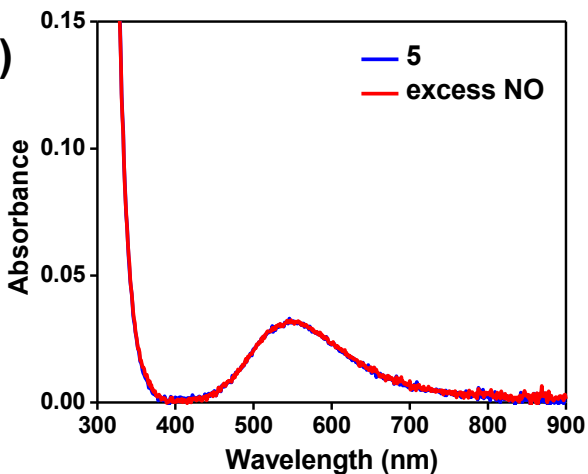

(d)

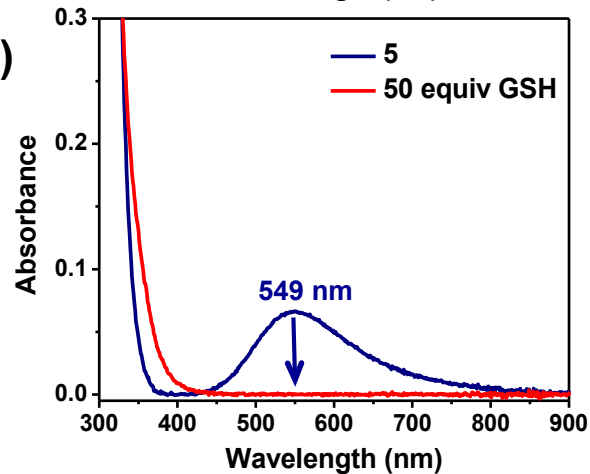

(f)

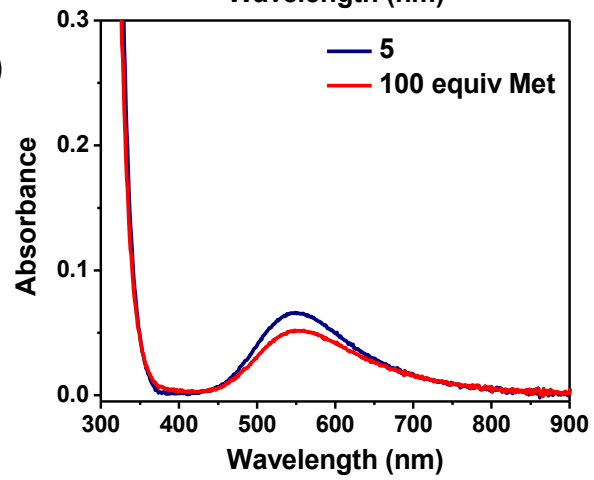

(h)

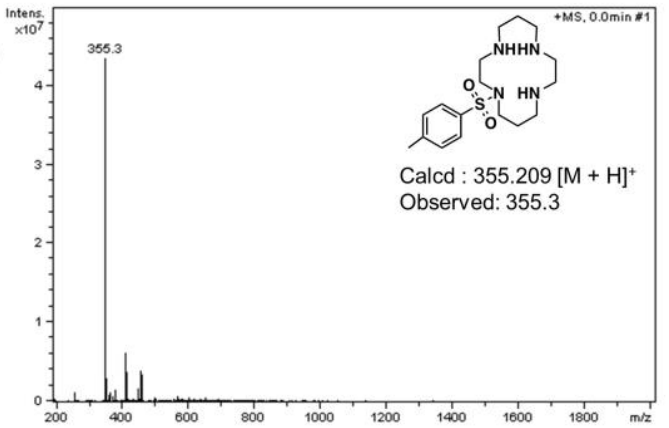

Figure S10. UV-vis spectra of a $0.42 \mathrm{mM}$ anaerobic solution of $\left[\mathrm{Cu}^{\mathrm{II}}\left(14-\mathrm{N}_{4}-\mathrm{Ts}\right)(\mathrm{OTf})_{2}\right](5)$ in $\mathrm{pH} 7$ aqueous buffer at $25{ }^{\circ} \mathrm{C}$ after addition of (a) 50 equiv of Angeli's salt (AS), (b) excess ( 2000 equiv) $\mathrm{NO}_{(\mathrm{g})}$, (c) excess $\mathrm{H}_{2} \mathrm{~S}_{(\mathrm{g})}$, (d) 50 equiv of glutathione (GSH), (e) 50 equiv of cysteine (Cys), (f) 100 equiv of methionine (Met), and (g) 50 equiv of $\mathrm{NaNO}_{2}$. (h) ESI(+)-MS spectrum of the solution of 5 after reaction with 50 equiv of AS. 


\section{Reactivity of 5 toward HNO in Methanol.}

(a)

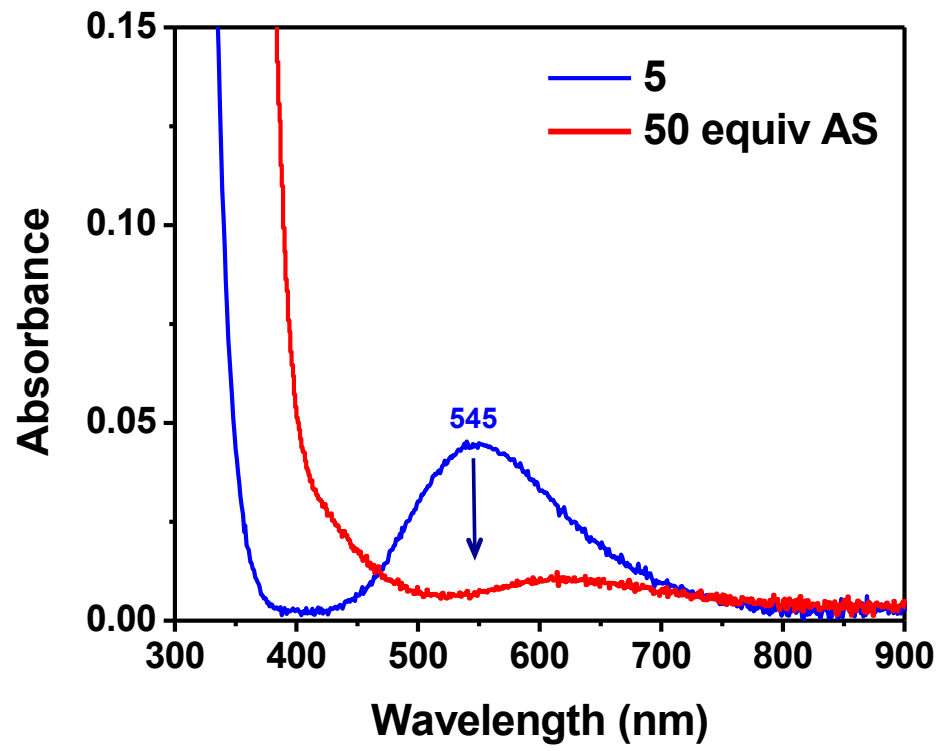

(b)

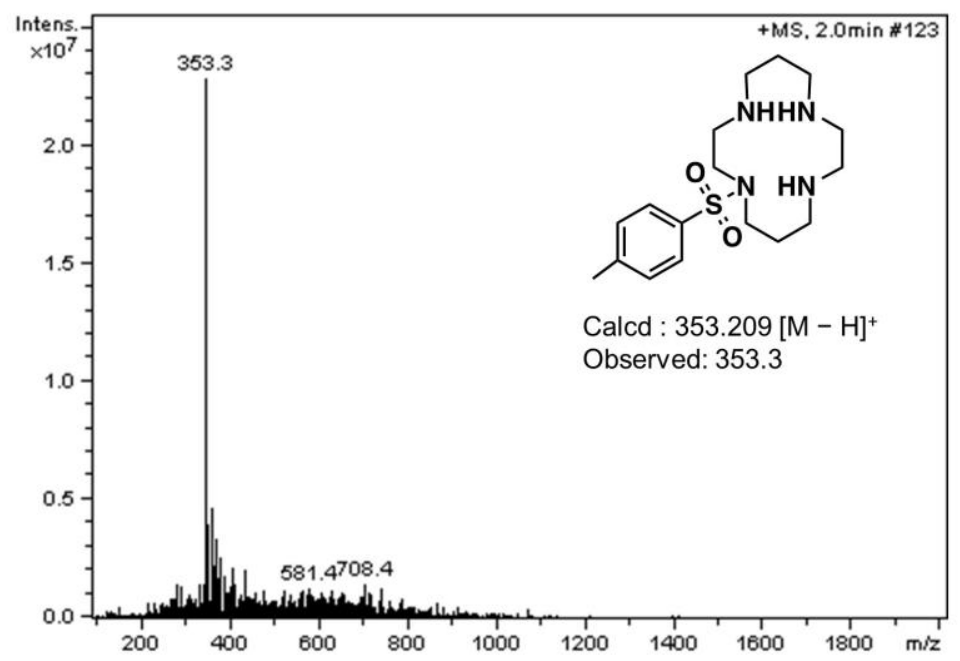

Figure S11. (a) UV-Vis spectra of anaerobic $0.33 \mathrm{mM}$ of $5\left(d-d\right.$ band: $\left.548 \mathrm{~nm}, \varepsilon=170 \mathrm{M}^{-1} \mathrm{~cm}^{-1}\right)$ in $\mathrm{MeOH}$, acquired before and after addition of 50 equiv of Angeli's salt (AS) and (b) ESI(+)-MS data from the reaction of 5 with 50 equiv of Angeli's salt (AS). $5(0.33 \mathrm{mM})$ was dissolved in $\mathrm{MeOH}$ in the dry box. An aliquot of the stock solution of the complex was placed in a gastight cuvette and taken out of the dry box. $100 \mu \mathrm{L}$ of Angeli's salt (50 equiv, $15 \mathrm{mM}$ in $0.01 \mathrm{M} \mathrm{NaOH}$ aq) was injected to the solution of 5 with a gastight syringe. 
(a) 5

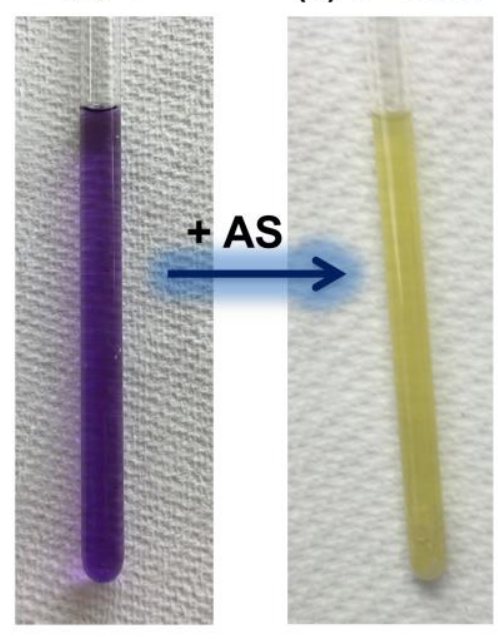

(c) Ligand in $\mathrm{CD}_{3} \mathrm{OD}$

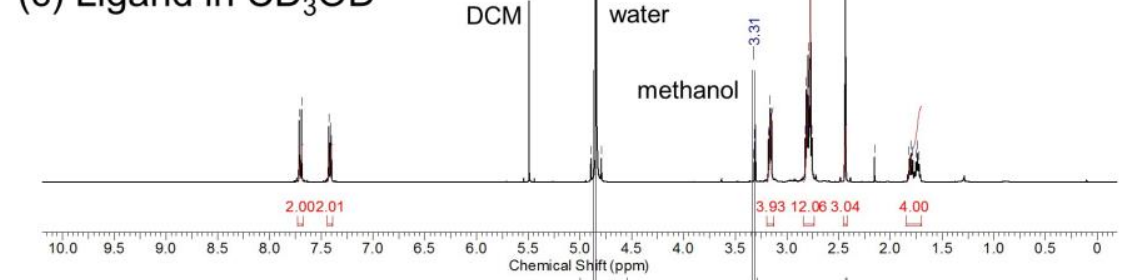

(b) $5+\mathrm{AS}$ in $\mathrm{CD}_{3} \mathrm{OD}$

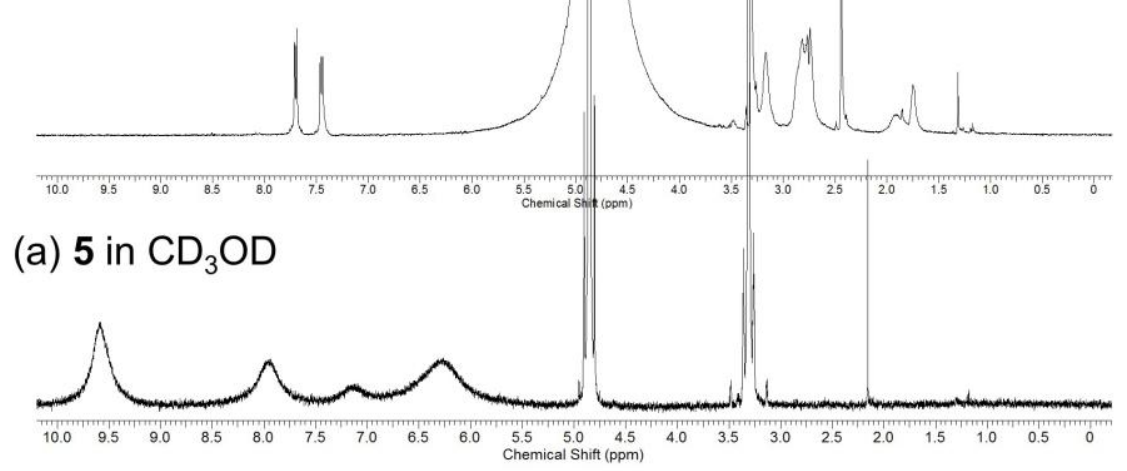

Figure S12. ${ }^{1} \mathrm{H}$ NMR spectra of (a) $\left[\mathrm{Cu}^{\mathrm{II}}\left(14-\mathrm{N}_{4}-\mathrm{Ts}\right)(\mathrm{OTf})_{2}\right]$ (5), (b) 5 with 50 equiv of Angeli's salt (AS), and (c) 14- $\mathrm{N}_{4}$-Ts ligand in $\mathrm{CD}_{3} \mathrm{OD}$. A $10 \mathrm{mM}$ solution of 5 was prepared by dissolving $8 \mathrm{mg}$ of 5 in $1 \mathrm{~mL}$ $\mathrm{CD}_{3} \mathrm{OD}$ in a dry box. A $650 \mu \mathrm{L}$ aliquot of this solution was added to a $5 \mathrm{~mm}$ NMR tube, capped with a rubber septum. The tube was then removed from the dry box and the ${ }^{1} \mathrm{H}$ NMR spectrum was acquired. A $35 \mu \mathrm{L}$ portion of $\mathrm{AS}$ (50 equiv, $500 \mathrm{mM}$ in $0.01 \mathrm{M} \mathrm{NaOH}$ aq) was injected to the NMR tube with a gastight syringe under $\mathrm{N}_{2}$ and the ${ }^{1} \mathrm{H}$ NMR spectrum was acquired. Before addition of AS, the ${ }^{1} \mathrm{H}$ NMR spectrum of 5 in $\mathrm{CD}_{3} \mathrm{OD}$ displayed broad resonances characteristic for paramagnetic $\mathrm{Cu}$ (II) complexes. After reaction with $\mathrm{HNO}$, the spectrum displayed sharp resonances similar to those of the metal-free ligand. For comparison, the ${ }^{1} \mathrm{H}$ NMR of the metal-free $14-\mathrm{N}_{4}$-Ts ligand in $\mathrm{CD}_{3} \mathrm{OD}$ is shown. 


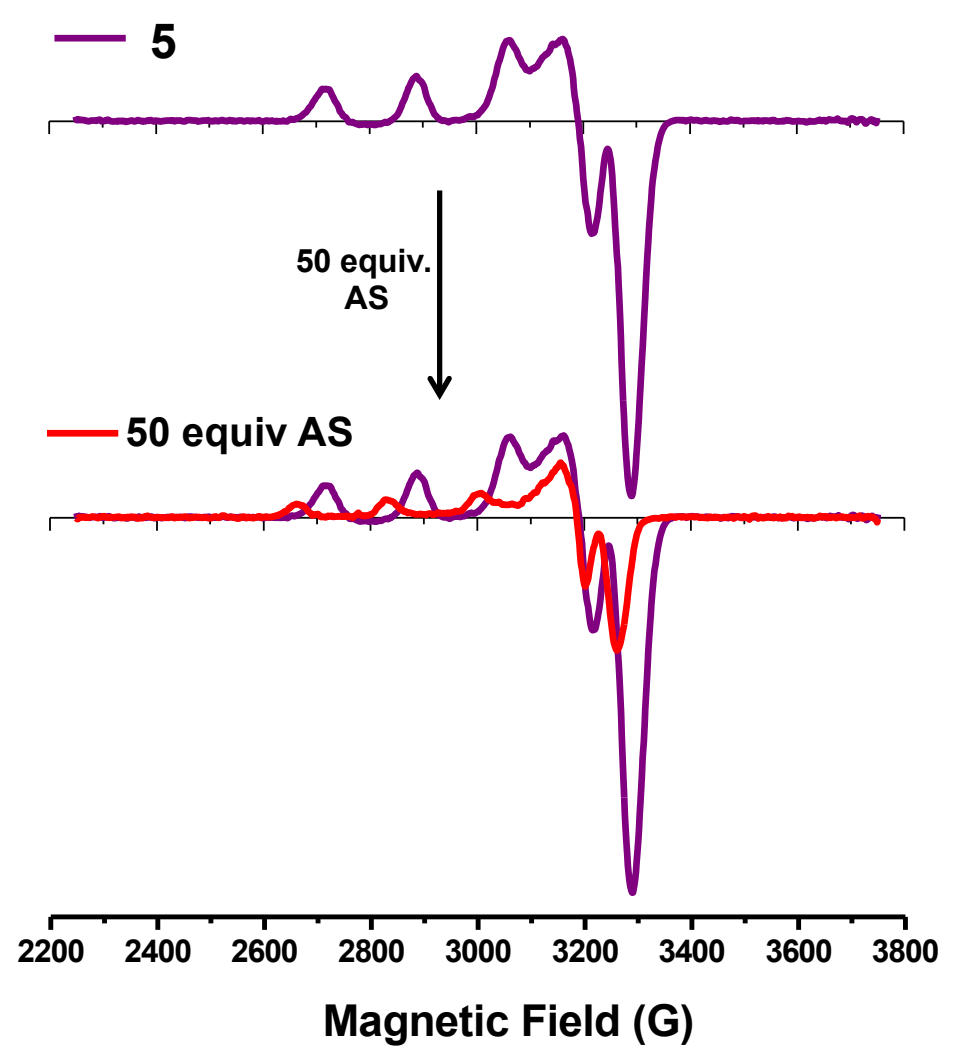

Figure S13. EPR spectra of the reaction solution of 5 with Angeli's salt (AS) in methanol. A 2 mM solution of 5 was prepared by dissolving $2.4 \mathrm{mg}$ of 5 in $1.6 \mathrm{~mL}$ of methanol in a dry box. A $400 \mu \mathrm{L}$ aliquot of this solution was placed in a $2 \mathrm{~mL}$ vial. A $50 \mu \mathrm{L}$ (50 equiv) portion of $100 \mathrm{mM}$ AS, obtained by dissolving $20 \mathrm{mg}$ of $\mathrm{AS}$ in $200 \mu \mathrm{L}$ of $0.01 \mathrm{M} \mathrm{NaOH}$ aq, were added and the resulting solution was transferred into a $2 \mathrm{~mm}$ EPR tube which was subsequently capped with a rubber septum, removed from the dry box, and frozen in liquid $\mathrm{N}_{2}$. Upon reaction with $\mathrm{HNO}$, a decrease in the intensity of the doubly integrated EPR signal was observed, indicating partial reduction of $\mathrm{Cu}$ (II) to $\mathrm{Cu}(\mathrm{I})$ with formation of a different $\mathrm{Cu}$ (II) species. This result is consistent with the ${ }^{1} \mathrm{H}$ NMR spectrum of Figure $\mathrm{S} 12$. 


\section{Reactivity of 5 toward $\mathrm{HO}^{-}$in $\mathrm{pH} 7$ Buffer and Methanol.}

(a)

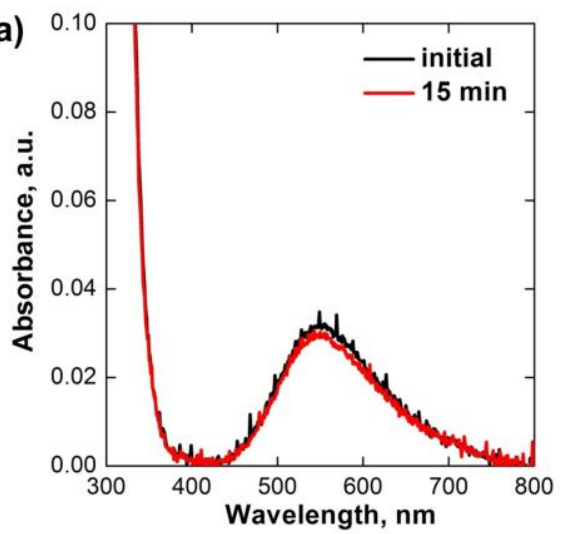

(b)

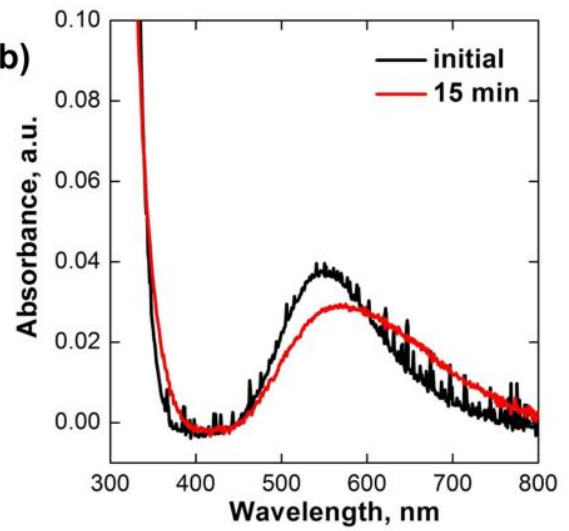

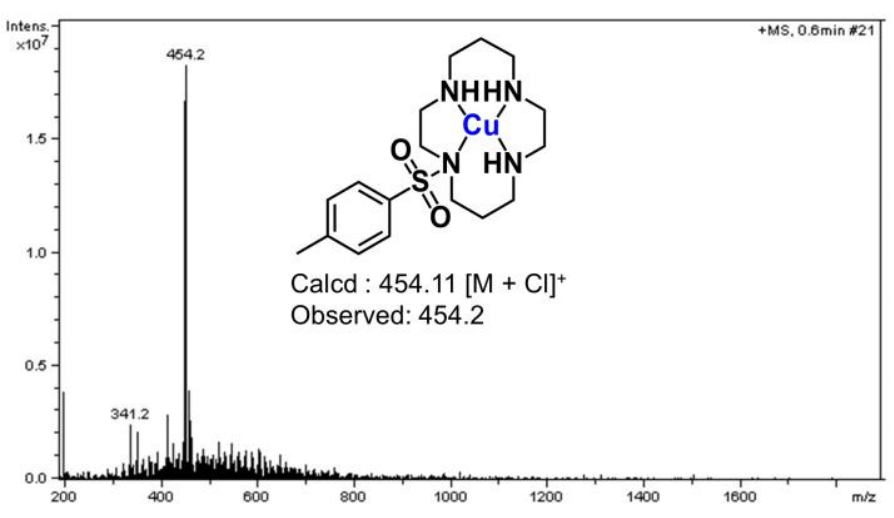

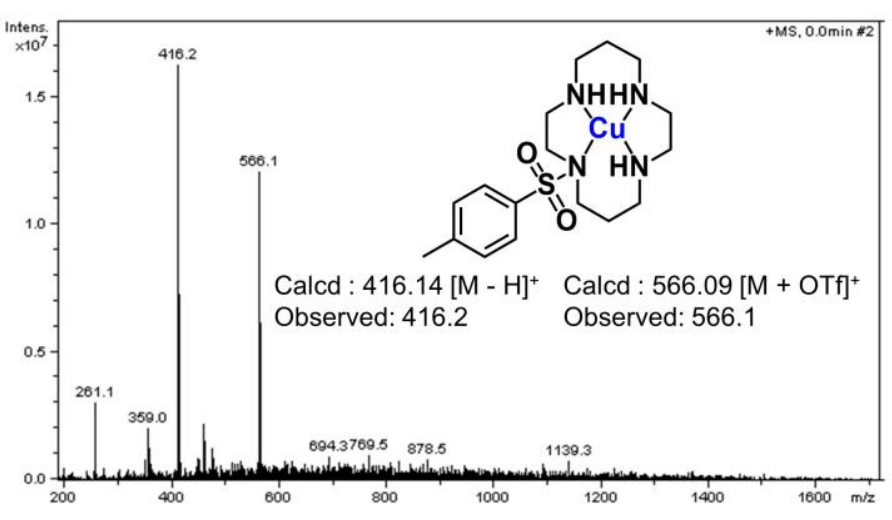

Figure S14. UV-Vis and ESI-MS spectra of $0.25 \mathrm{mM}$ solutions of 5 in (a) $\mathrm{pH} 7$ aqueous buffer (50 $\mathrm{mM}$ PIPES, $100 \mathrm{mM} \mathrm{KCl}$ ) and (b) $\mathrm{MeOH}$, acquired before and $15 \mathrm{~min}$ after addition of 2 equiv of $\mathrm{NaOH}(100$ $\mu \mathrm{L}$ of $0.01 \mathrm{M} \mathrm{NaOH}$ aq). Mass spectra of the solutions were acquired after $15 \mathrm{~min}$ in the positive mode. 


\section{Reactivity of 6 toward HNO in pH 7 Buffer.}

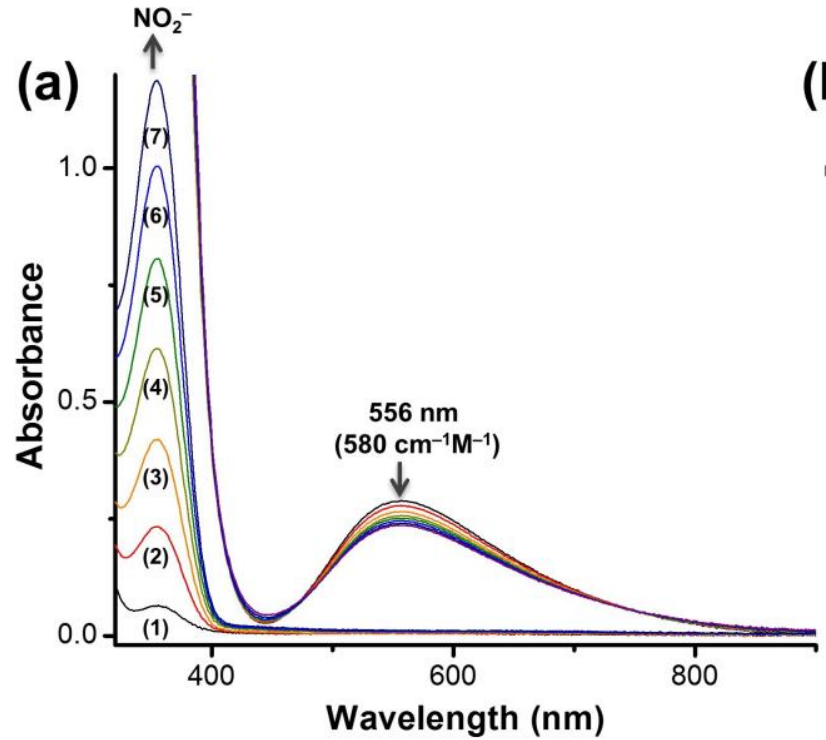

(b)

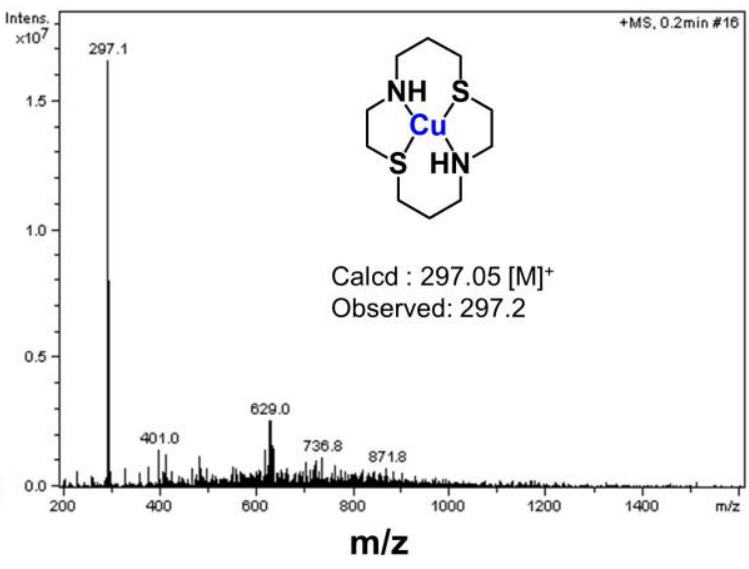

Figure S15. UV-vis spectra of an anaerobic $0.5 \mathrm{mM}$ solution of $\left[\mathrm{Cu}^{\mathrm{II}}\left(14-\mathrm{N}_{2} \mathrm{~S}_{2}\right)(\mathrm{OTf})_{2}\right] 6$ in aqueous buffer (50 mM PIPES, $100 \mathrm{mM} \mathrm{KCl,} \mathrm{pH} \mathrm{7.0),} \mathrm{recorded} \mathrm{upon} \mathrm{repeated} \mathrm{addition} \mathrm{of} 10$ equiv of AS (airfree solution in $0.01 \mathrm{M} \mathrm{NaOH} \mathrm{aq}$ ) and subsequent oxygenation (10 min) and degassing (15 min) with $\mathrm{N}_{2}$. (b) Low-resolution mass spectrum (ESI+) of the final solution of 6 after 7 successive additions of 10 equiv of $\mathrm{AS}$ in aqueous buffer (50 mM PIPES, $100 \mathrm{mM} \mathrm{KCl,} \mathrm{pH} \mathrm{7.0).}$
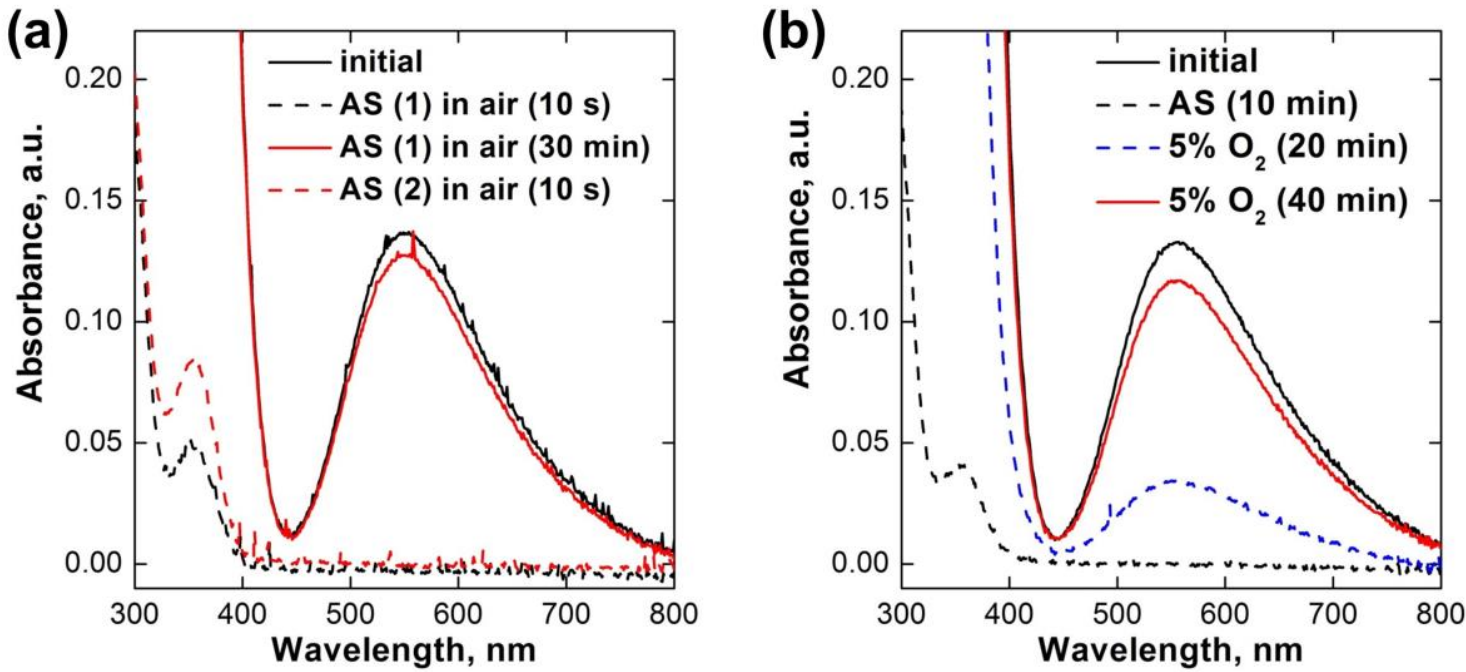

Figure S16. (a) UV-vis spectra of an aerobic $0.25 \mathrm{mM}$ solution of $\left[\mathrm{Cu}^{\mathrm{II}}\left(14-\mathrm{N}_{2} \mathrm{~S}_{2}\right)(\mathrm{OTf})_{2}\right](\mathbf{6})$ in aqueous buffer (50 mM PIPES, $100 \mathrm{mM} \mathrm{KCl,} \mathrm{pH} \mathrm{7.0),} \mathrm{recorded} \mathrm{upon} \mathrm{repeated} \mathrm{addition} \mathrm{of} 10$ equiv of AS (100 $\mu \mathrm{L}$ of a $50 \mathrm{mM}$ air-free solution in $0.01 \mathrm{M} \mathrm{NaOH} \mathrm{aq}$ ) and subsequent aeration (30 min). (b) UV-vis spectra of an anaerobic $0.25 \mathrm{mM}$ solution of $\left[\mathrm{Cu}^{\mathrm{II}}\left(14-\mathrm{N}_{2} \mathrm{~S}_{2}\right)(\mathrm{OTf})_{2}\right](6)$ in $\mathrm{pH} 7$ aqueous buffer, recorded upon addition of 10 equiv of $\mathrm{AS}(100 \mu \mathrm{L}$ of a $50 \mathrm{mM}$ air-free solution in $0.01 \mathrm{M} \mathrm{NaOH}$ aq) and subsequent injection of $200 \mu \mathrm{L}$ pure $\mathrm{O}_{2}$ gas into the headspace of the $4.0 \mathrm{~mL}$ cuvette with an airtight syringe. 


\section{Reactivity of 6 toward $\mathrm{HO}^{-}$in $\mathrm{pH} 7$ Buffer and Methanol.}

(a)

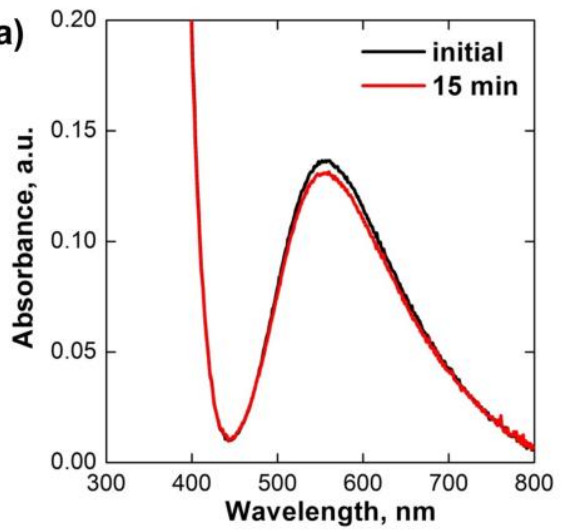

(b)

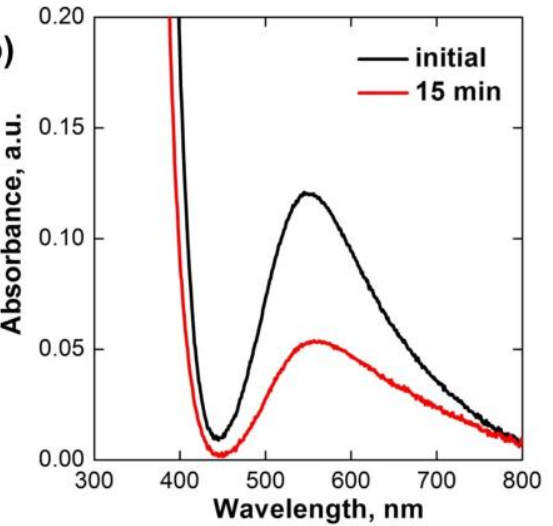

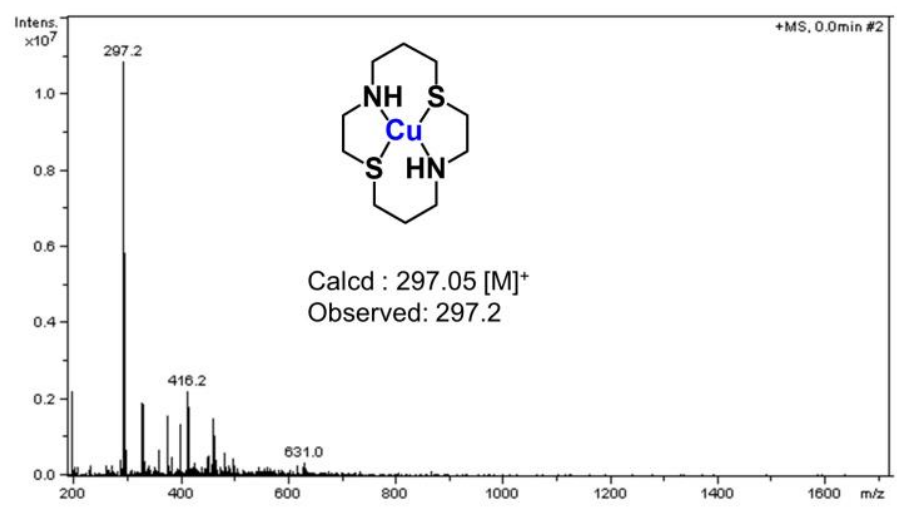

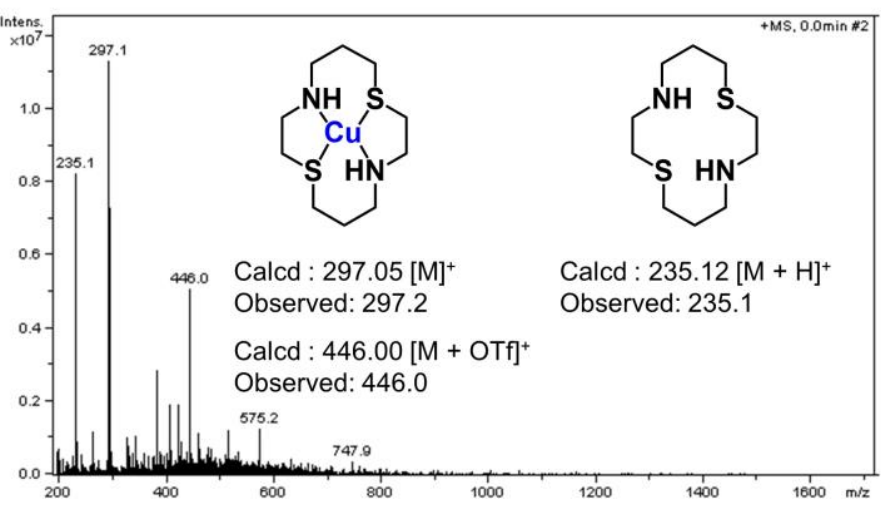

Figure S17. UV-Vis and ESI-MS spectra of $0.25 \mathrm{mM}$ solutions of 6 in (a) $\mathrm{pH} 7$ aqueous buffer (50 mM PIPES, $100 \mathrm{mM} \mathrm{KCl}$ ) and (b) $\mathrm{MeOH}$, acquired before and 15 min after addition of 2 equiv of $\mathrm{NaOH}(100$ $\mu \mathrm{L}$ of $0.01 \mathrm{M} \mathrm{NaOH}$ aq). Mass spectra of the solutions were acquired after $15 \mathrm{~min}$ in the positive mode. 
10. Reactivity of 6 toward NO, $\mathrm{NaNO}_{2}, \mathrm{H}_{2} \mathrm{~S}$, GSH, Cys, and Met in pH 7 Buffer.

(a)

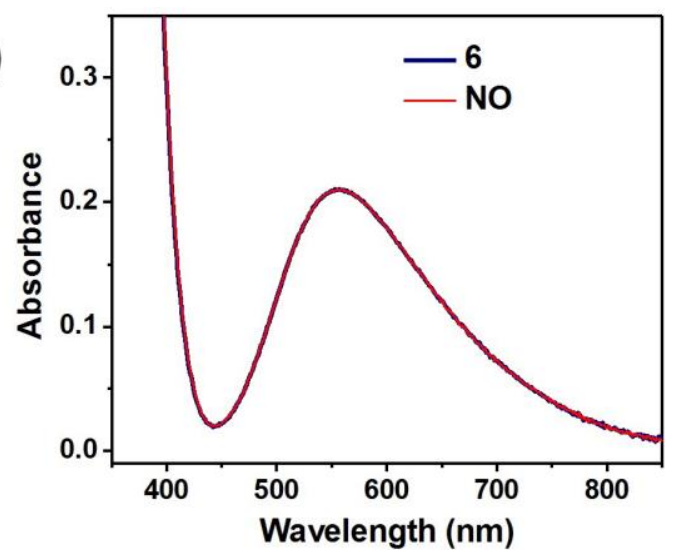

(c)

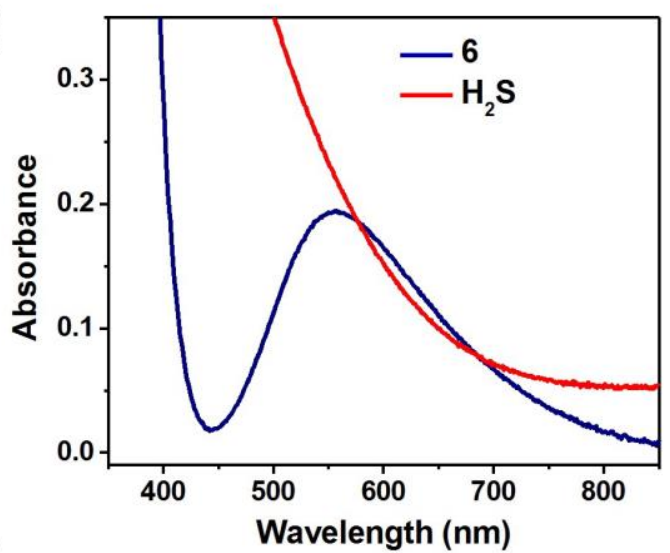

(e)

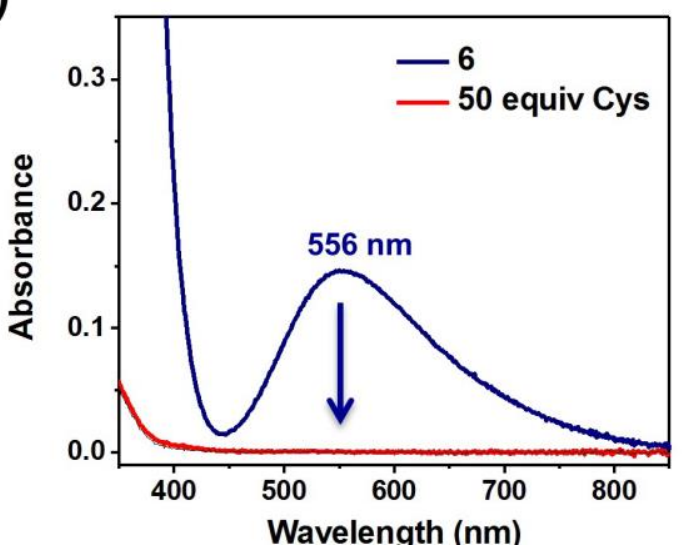

(b)

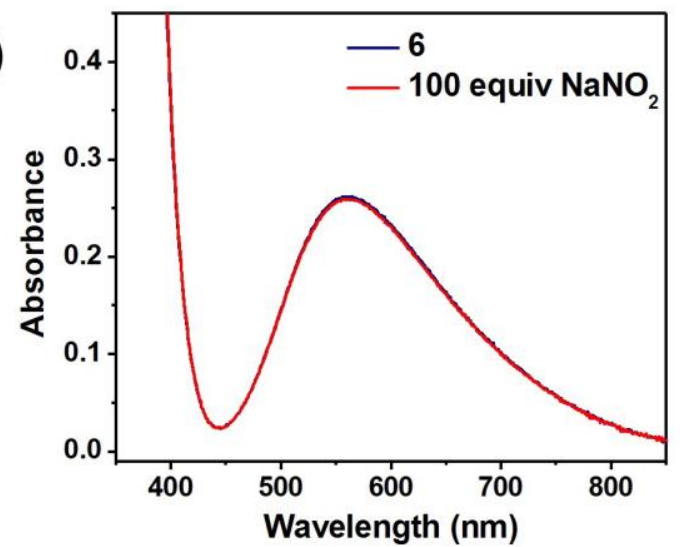

(d)

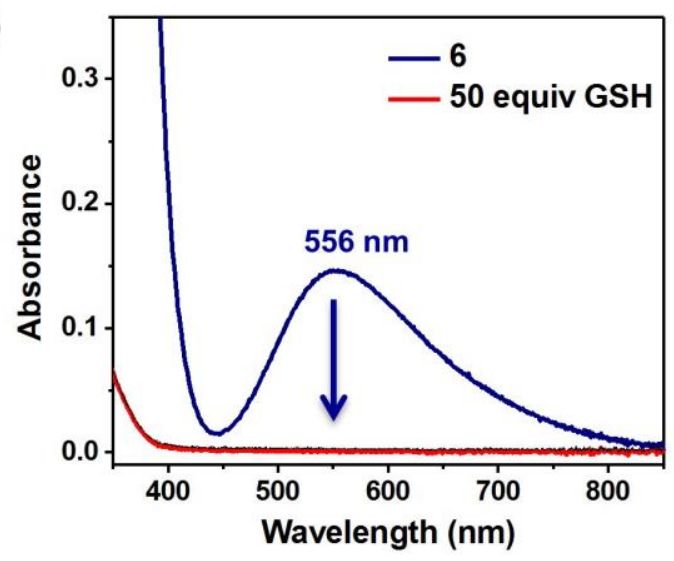

(f)

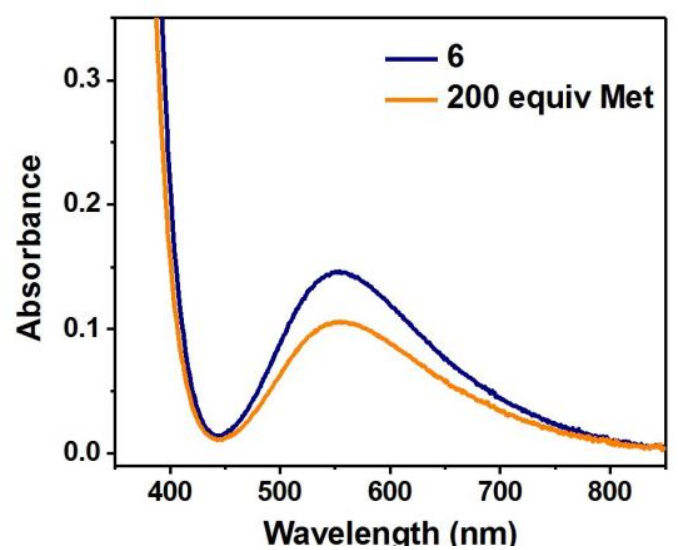

Figure S18. UV-vis spectra of anaerobic $0.50 \mathrm{mM}$ solutions of $\left[\mathrm{Cu}^{\mathrm{II}}\left(14-\mathrm{N}_{2} \mathrm{~S}_{2}\right)(\mathrm{OTf})_{2}\right](6)$ in $\mathrm{pH} 7$ aqueous buffer ( $d-d$ band: $\left.556 \mathrm{~nm}, \varepsilon=580 \mathrm{M}^{-1} \mathrm{~cm}^{-1}\right)$, acquired before and after addition of (a) excess ( 2000 equiv) $\mathrm{NO}_{(\mathrm{g})}$, (b) 100 equiv of $\mathrm{NaNO}_{2}$, (c) excess (>2000 equiv) $\mathrm{H}_{2} \mathrm{~S}_{(\mathrm{g})}$, (d) 50 equiv of $\mathrm{GSH}$, (e) 50 equiv of Cys, and (f) 50 equiv of Met at $25^{\circ} \mathrm{C}$. 
11. Reactivity of 6 toward $\mathrm{HNO}$ in the Presence of 100 Equiv of $\mathrm{NaNO}_{2}$ in Buffer.

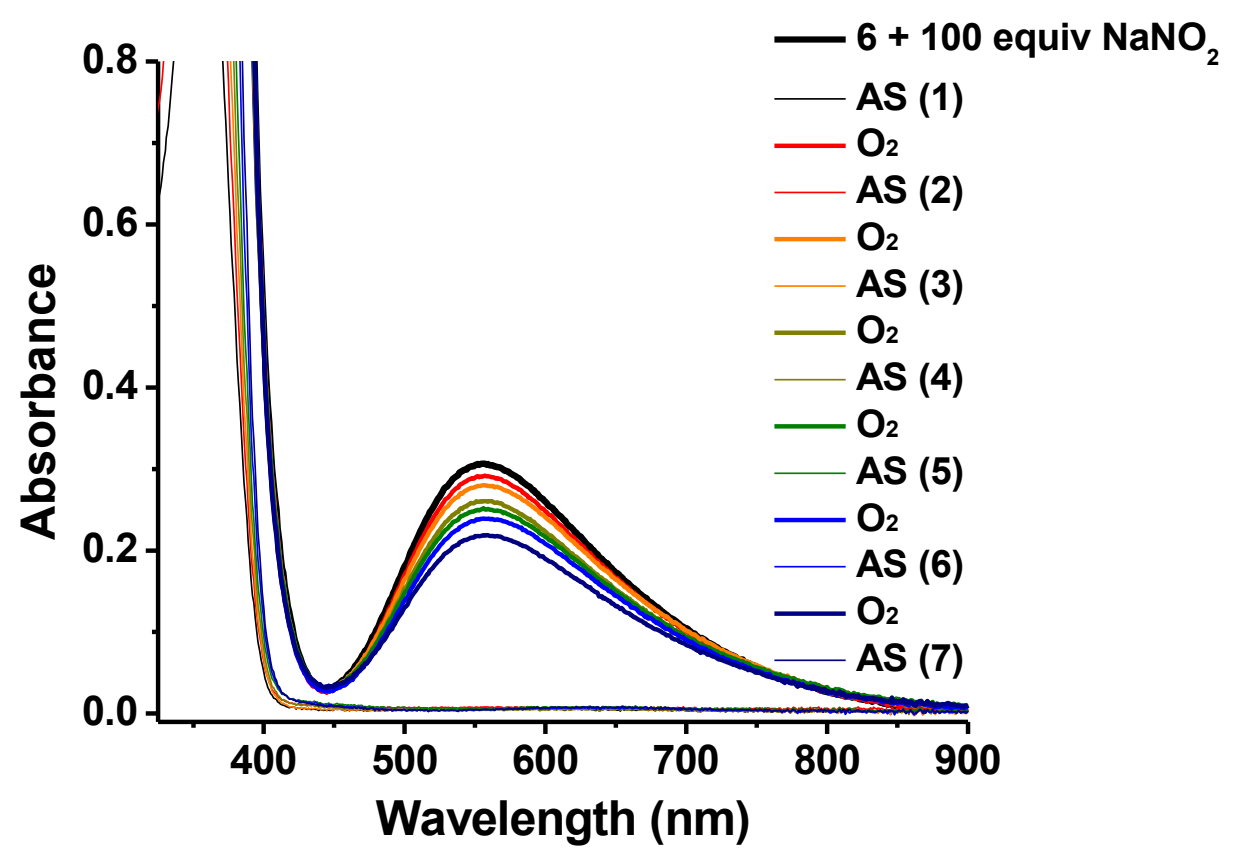

Figure S19. UV-vis spectra of an anaerobic $0.57 \mathrm{mM}$ solution of 6 in the presence of 100 equiv of $\mathrm{NaNO}_{2}$ in aqueous buffer (50 mM PIPES, $100 \mathrm{mM} \mathrm{KCl,} \mathrm{pH} \mathrm{7.0),} \mathrm{recorded} \mathrm{upon} \mathrm{repeated} \mathrm{addition} \mathrm{of} 10$ equiv of $\mathrm{AS}$ and subsequent oxygenation (10 min) and degassing (15 min) with $\mathrm{N}_{2}$. 
12. Reactivity of 6 toward HNO Monitored by ${ }^{1}$ H NMR Spectroscopy.

(a)

(b)
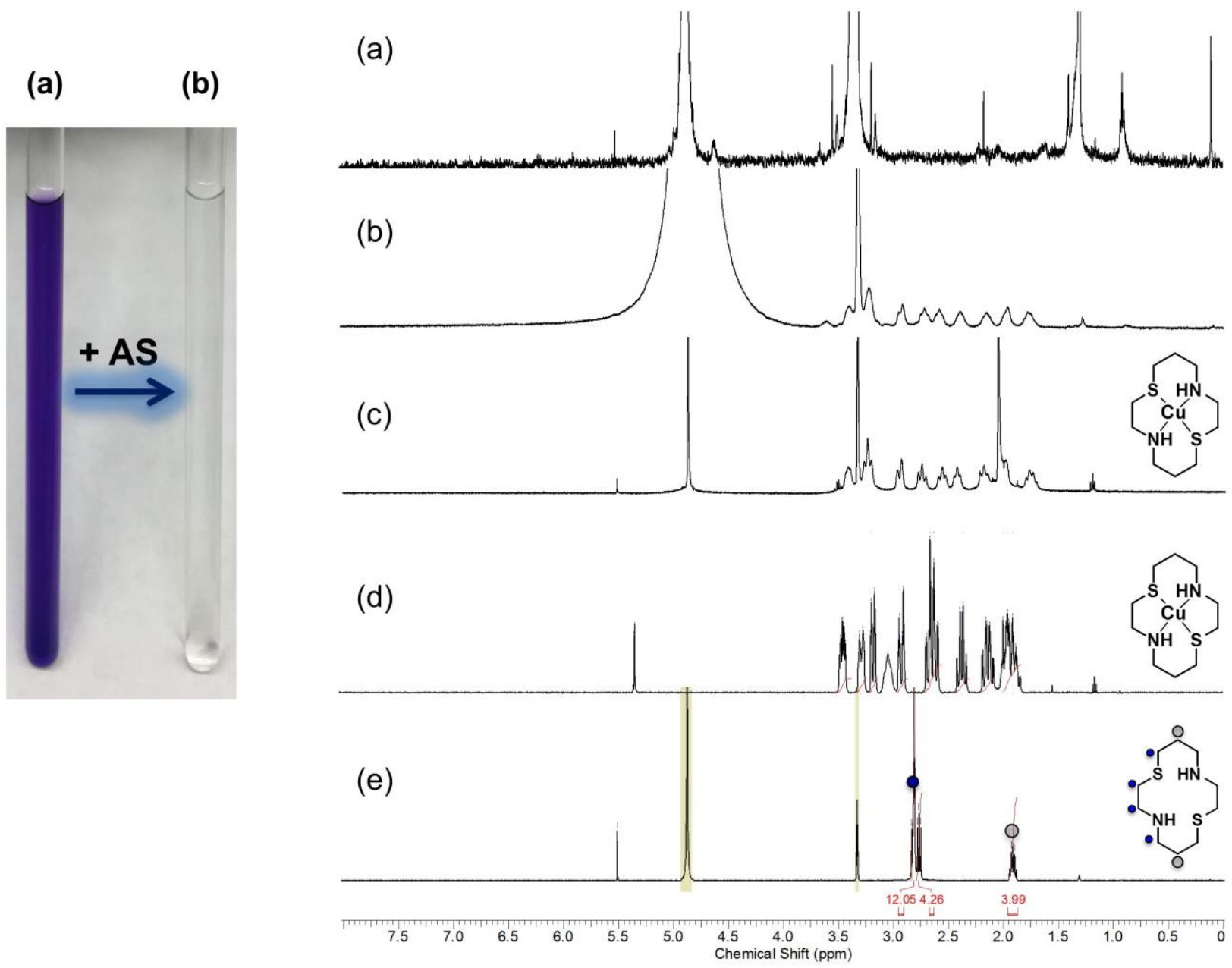

Figure S20. ${ }^{1} \mathrm{H}$ NMR spectra of $10 \mathrm{mM}$ of 6 (a) before and (b) after addition of 10 equiv of AS in $\mathrm{CD}_{3} \mathrm{OD}$. Before addition of AS, the ${ }^{1} \mathrm{H}$ NMR spectrum of $\mathbf{6}$ displayed broad resonances characteristic for paramagnetic $\mathrm{Cu}$ (II) complexes. After addition of $\mathrm{AS}$, the reaction solution displayed sharper resonances. For comparison, ${ }^{1} \mathrm{H}$ NMR spectra of (c) $\left[\mathrm{Cu}^{\mathrm{I}}\left(14-\mathrm{N}_{2} \mathrm{~S}_{2}\right)\right]\left(\mathrm{PF}_{6}\right)$ (7) in $\mathrm{CD}_{3} \mathrm{OD}$ and (d) 7 in $\mathrm{CD}_{2} \mathrm{Cl}_{2}$ are shown. (e) ${ }^{1} \mathrm{H}$ NMR spectrum of metal-free $14-\mathrm{N}_{2} \mathrm{~S}_{2}$ ligand in $\mathrm{CD}_{3} \mathrm{OD}$. 


\section{Reactivity of 6 toward HNO at Different pH Values.}

(a)
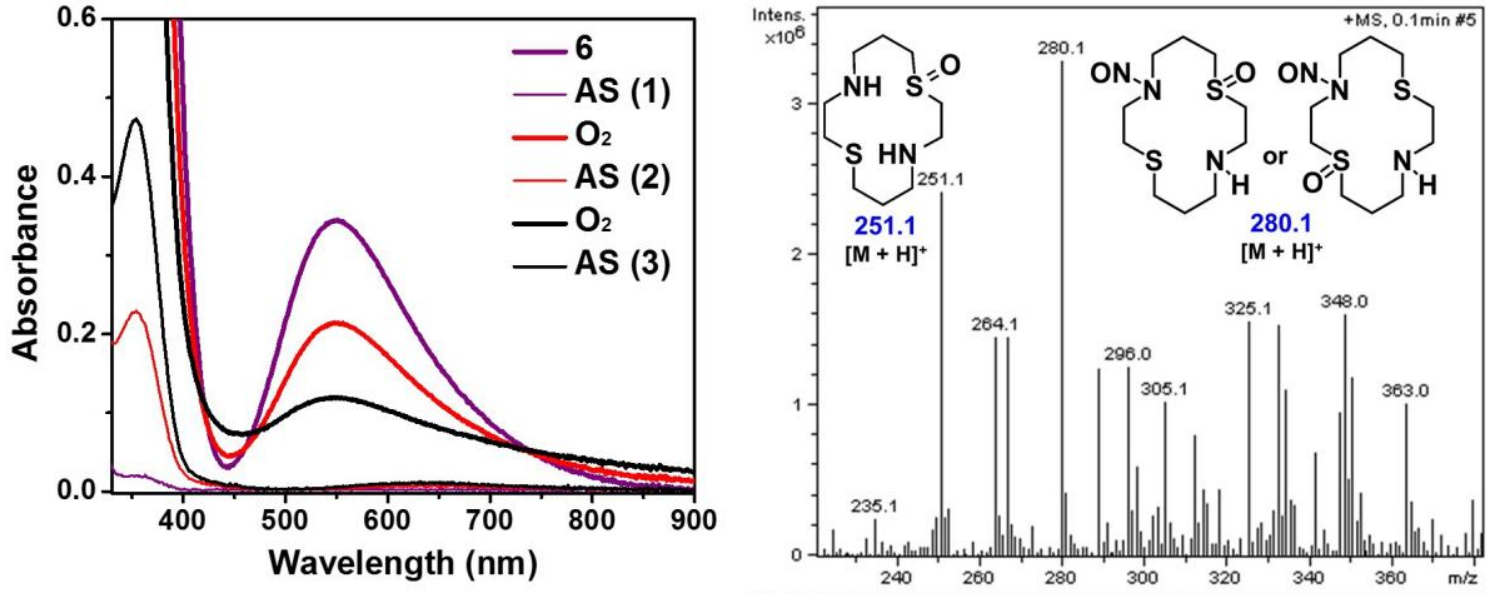

(b)
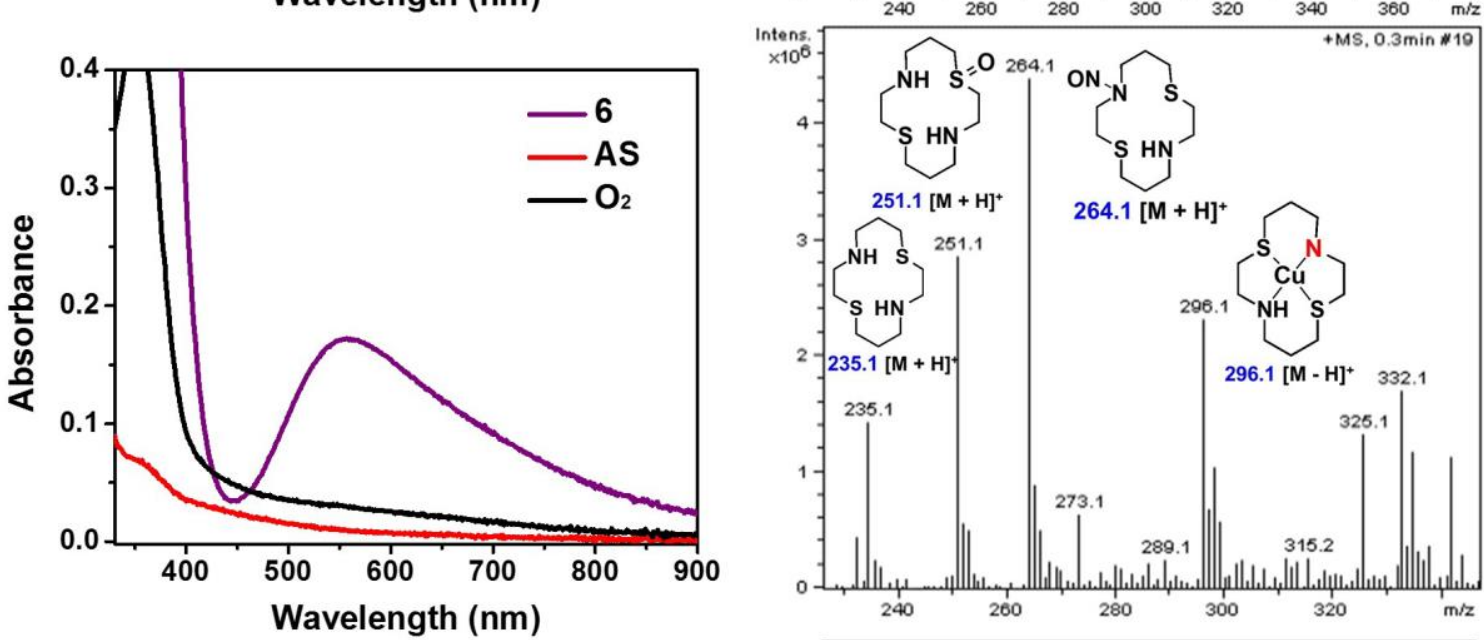

(c)
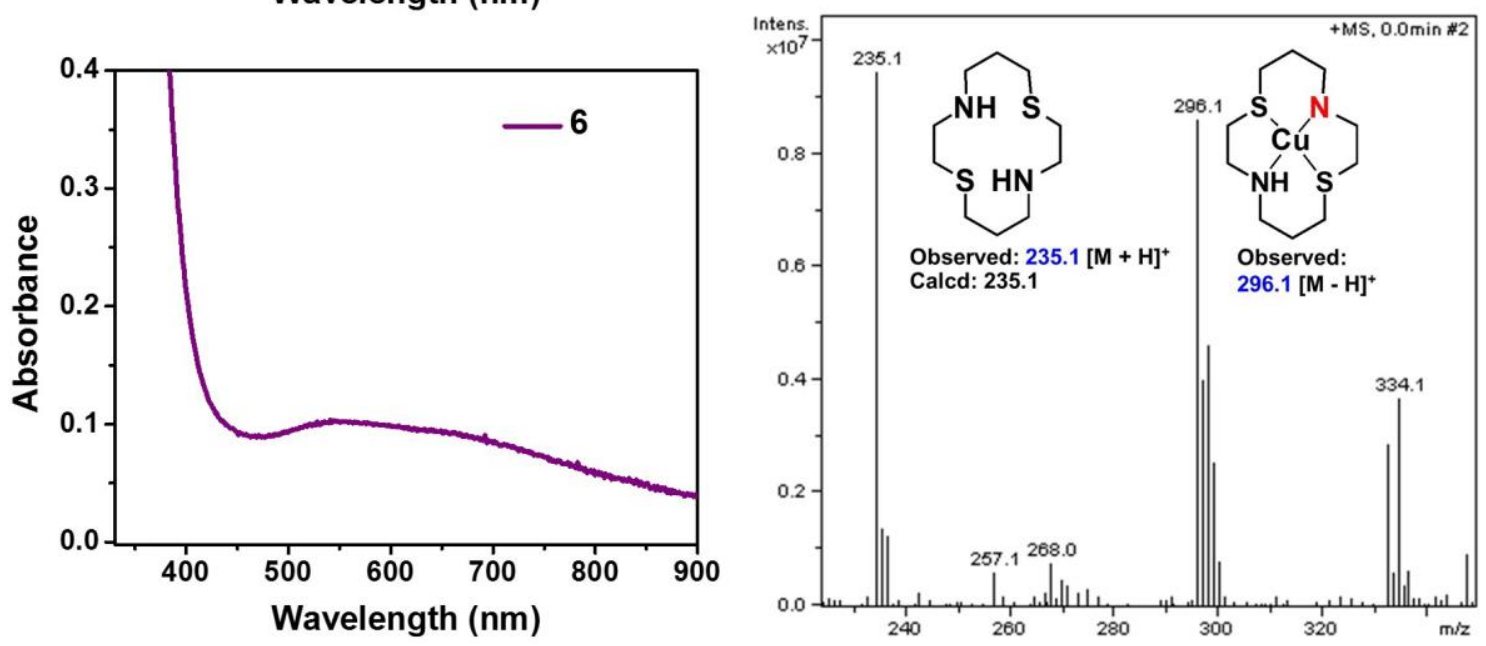

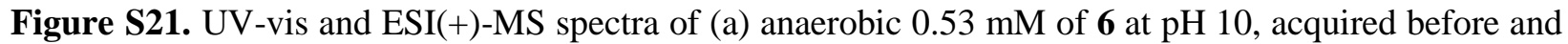
after addition of 10 equiv of AS, (b) anaerobic $0.50 \mathrm{mM}$ of 6 at $\mathrm{pH} 12$, acquired before and after addition of 10 equiv of $\mathrm{AS}$, and (c) anaerobic $0.50 \mathrm{mM}$ of 6 at pH $14\left(50 \mathrm{mM}\right.$ PIPES, $100 \mathrm{mM} \mathrm{KCl}, 25{ }^{\circ} \mathrm{C}, \mathrm{pH}$ adjusted by addition of $\sim 1 \mathrm{M} \mathrm{NaOH}$ aq). 


\section{Reactivity of 6 toward HNO and NO in pH 7 Buffer.}
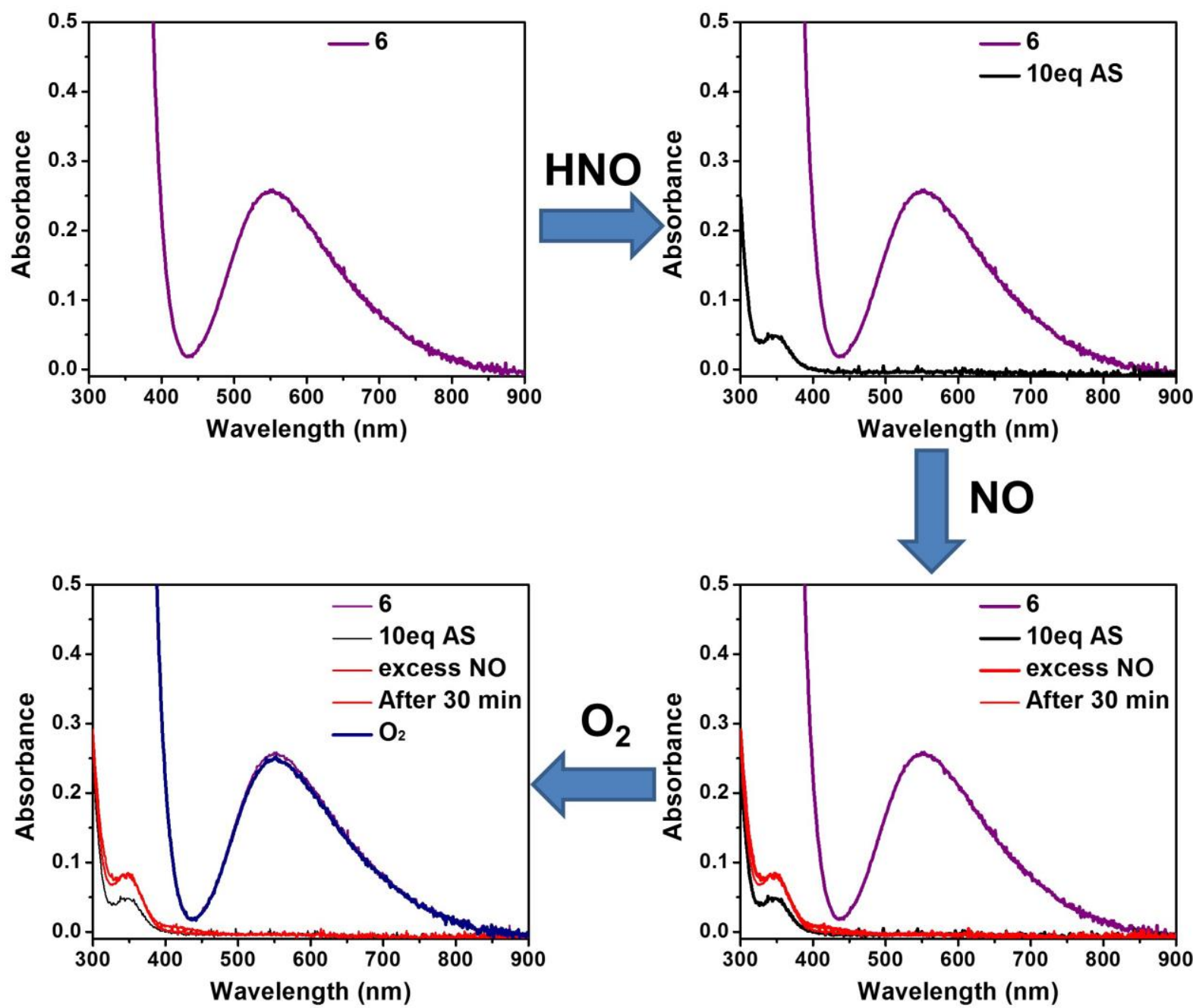

Figure S22. UV-vis spectra of an anaerobic $0.5 \mathrm{mM}$ solution of 6 in aqueous buffer (50 mM PIPES, 100 $\mathrm{mM} \mathrm{KCl}, \mathrm{pH} 7.0$ ), recorded upon addition of 10 equiv of $\mathrm{AS}$ resulting in reduction of $\mathrm{Cu}$ (II) to $\mathrm{Cu}(\mathrm{I})$, followed by subsequent addition of excess $\mathrm{NO}$ and sparging with $\mathrm{O}_{2}$. 
15. Reactivity of 7 toward NO in pH 7 Buffer.

(a)

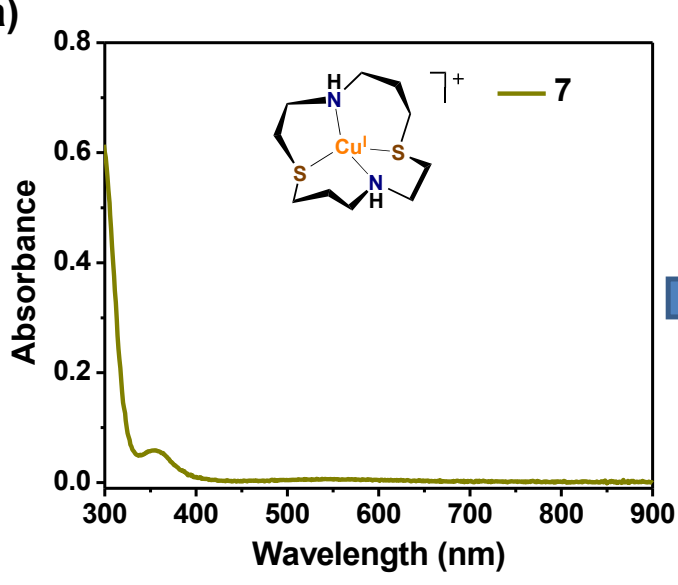

(b)

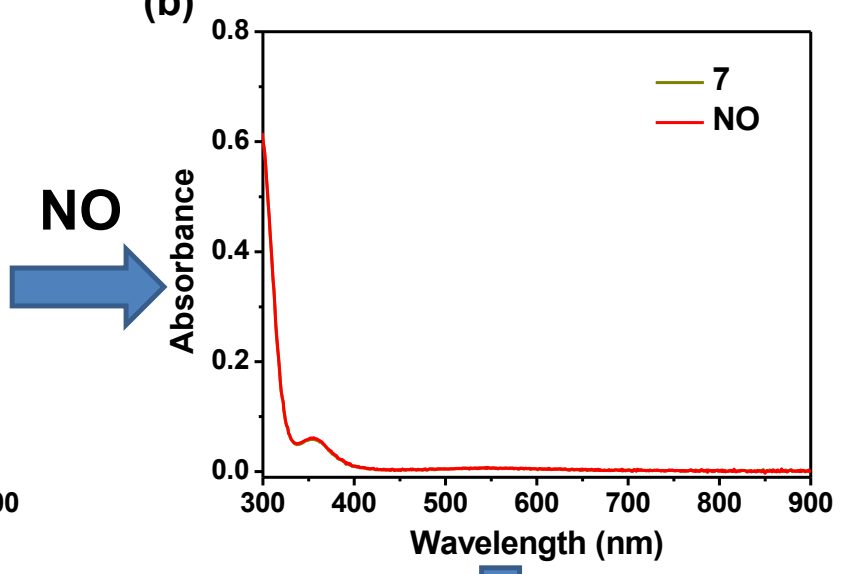

(c)

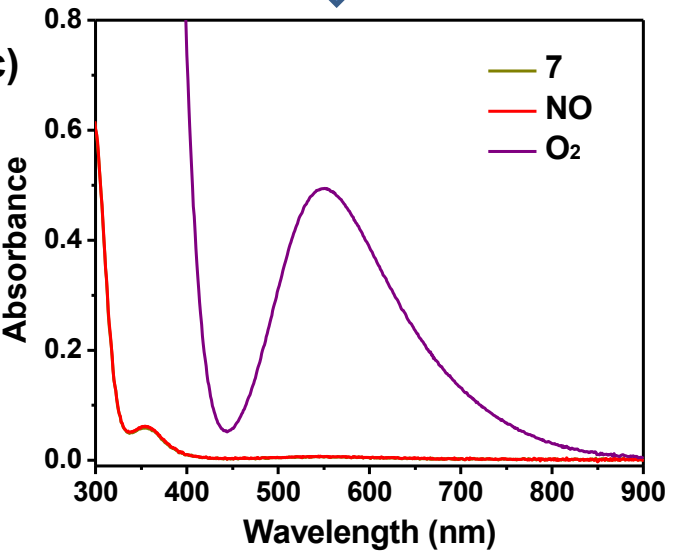

Figure S23. UV-vis spectra of an anaerobic $0.50 \mathrm{mM}$ solution of $\left[\mathrm{Cu}^{\mathrm{I}}\left(14-\mathrm{N}_{2} \mathrm{~S}_{2}\right)\right]\left(\mathrm{PF}_{6}\right)$ (7) in $\mathrm{pH} 7$ aqueous buffer, acquired (a) before and (b) after addition of 1500 equiv of $\mathrm{NO}_{(\mathrm{g})}$, followed by (c) oxygenation by $\mathrm{O}_{2}$ purging for $10 \mathrm{~min}$. 


\section{References.}

(1) King, S. B.; Nagasawa, H. T. Methods Enzymol. 1999, 301, 211-220.

(2) Royal, G.; Dahaoui-Gindrey, V.; Dahaoui, S.; Tabard, A.; Guilard, R.; Pullumbi, P.; Lecomte, C. Eur. J. Org. Chem. 1998, 1998, 1971-1975.

(3) Halfen, J. A.; Young, J. V. G. Chem. Commun. 2003, 2894-2895.

(4) Walker, T. L.; Malasi, W.; Bhide, S.; Parker, T.; Zhang, D.; Freedman, A.; Modarelli, J. M.; Engle, J. T.; Ziegler, C. J.; Custer, P.; Youngs, W. J.; Taschner, M. J. Tetrahedron Lett. 2012, 53, 6548-6551.

(5) Gottlieb, H. E.; Kotlyar, V.; Nudelman, A. J. Org. Chem. 1997, 62, 7512-7515.

(6) Stoll, S.; Schweiger, A. J. Magn. Reson. 2006, 178, 42-55.

(7) APEX2 v.4.0, Bruker AXS, Inc.: Madison, WI, 2008.

(8) SAINT: SAX Area-Detector Integration Program, University of Göttingen: Göttingen, Germany, 2008.

(9) Sheldrick, G. M. SADABS: Area-Detector Absorption Correction, University of Göttingen: Göttingen, Germany, 2008.

(10) Sheldrick, G. M. Acta Crystallogr. Sect. A 2015, 71, 3-8.

(11) Spek, A. L. PLATON: A Multipurpose Crystallographic Tool, University of Utrecht: Utrecht, The Netherlands, 2008.

(12) Dolomanov, O. V.; Bourhis, L. J.; Gildea, R. J.; Howard, J. A. K.; Puschmann, H. J. Appl. Cryst. 2009, 42, 339-341. 